\title{
Transplanted Neuroblasts Differentiate Appropriately into Projection Neurons with Correct Neurotransmitter and Receptor Phenotype in Neocortex Undergoing Targeted Projection Neuron Degeneration
}

\author{
Jennifer J. Shin, Rosemary A. Fricker-Gates, Francisco A. Perez, Blair R. Leavitt, David Zurakowski, and \\ Jeffrey D. Macklis \\ Division of Neuroscience, Children's Hospital, Department of Neurology and Program in Neuroscience, Harvard Medical \\ School, Boston, Massachusetts 02115
}

\begin{abstract}
Reconstruction of complex neocortical and other CNS circuitry may be possible via transplantation of appropriate neural precursors, guided by cellular and molecular controls. Although cellular repopulation and complex circuitry repair may make possible new avenues of treatment for degenerative, developmental, or acquired CNS diseases, functional integration may depend critically on specificity of neuronal synaptic integration and appropriate neurotransmitter/receptor phenotype.

The current study investigated neurotransmitter and receptor phenotypes of newly incorporated neurons after transplantation in regions of targeted neuronal degeneration of cortical callosal projection neurons (CPNs). Donor neuroblasts were compared to the population of normal endogenous CPNs in their expression of appropriate neurotransmitters (glutamate, aspartate, and GABA) and receptors (kainate-R, AMPA-R, NMDA-R. and GABA$R$ ), and the time course over which this phenotype developed after transplantation.

Transplanted immature neuroblasts from embryonic day 17 (E17) primary somatosensory (S1) cortex migrated to cortical layers undergoing degeneration, differentiated to a mature CPN
\end{abstract}

phenotype, and received synaptic input from other neurons. In addition, $23.1 \pm 13.6 \%$ of the donor-derived neurons extended appropriate long-distance callosal projections to the contralateral S1 cortex. The percentage of donor-derived neurons expressing appropriate neurotransmitters and receptors showed a steady increase with time, reaching numbers equivalent to adult endogenous CPNs by 4-16 weeks after transplantation.

These results suggest that previously demonstrated changes in gene expression induced by synchronous apoptotic degeneration of adult CPNs create a cellular and molecular environment that is both permissive and instructive for the specific and appropriate maturation of transplanted neuroblasts. These experiments demonstrate, for the first time, that newly repopulating neurons can undergo directed differentiation with high fidelity of their neurotransmitter and receptor phenotype, toward reconstruction of complex CNS circuitry.

Key words: neurotransmitters; receptors; glutamate; aspartate; GABA; kainate-R; NMDA-R; AMPA-R; GABA-R; targeted photolysis; apoptosis; neuronal degeneration; transplantation; migration; integration; neocortex
Transplantation of exogenous neuroblasts or neural progenitor cells may provide a means to repopulate diseased cortex with competent neurons and to reconstruct complex circuitry (Castro et al., 1988, 1991; Sørensen et al., 1990; Macklis, 1993; Sheen and Macklis, 1995; Schulz et al., 1995; Hernit-Grant and Macklis, 1996; Snyder et al., 1997). However, to reinstate accurate neuronal connectivity and function, transplanted neuroblasts must be able not only to form long-distance axonal connections with the host brain, but they must also be able to acquire a precise mature neuronal phenotype, expressing appropriate neurotransmitters and their receptors, which are crucial for synaptic processing and neuron function.

Neurotransmitters and their receptors are expressed in specific patterns to allow correct communication between neurons (Lipton and Kater, 1989; Vickers et al., 1993; He et al., 1998; Ozawa et al., 1998). In the neocortex, most pyramidal neurons use glutamate and/or aspartate to mediate rapid excitation, and receive synaptic input via GABA and glutamate (Fagg et al., 1983; Dori et al.,

Received Feb. 14, 2000; revised July 3, 2000; accepted July 19, 2000.

This work was supported by National Institutes of Health Grants HD28478 and MRRC HD18655, and the Alzheimer's Association. J.J.S. was supported by a Howard Hughes Medical Institute medical student fellowship. R.A.F. was partially supported by fellowships from the Wills Foundation and the Lefler Foundation. B.R.L. was partially supported by a Canadian Medical Research Council postdoctoral fellowship. We thank Cindy Tai for excellent technical support, Dr. Monte Gates for scientific guidance and input, and Thomas Y. Lin for valuable advice and support throughout the project.

J.J.S. and R.A.F. contributed equally to this work.

Correspondence should be addressed to Jeffrey D. Macklis, 354 Enders Building, 320 Longwood Avenue, Boston, MA 02115. E-mail: macklis@a1.tch.harvard.edu. Copyright (C) 2000 Society for Neuroscience 0270-6474/00/207404-13\$15.00/0
1992). In contrast, the majority of nonpyramidal interneurons use GABA to exert rapid inhibition on adjacent pyramidal neurons (McCormick et al., 1993). More specifically, studies suggest that the most appropriate markers for callosal projection neurons (CPNs) situated in layers II/III and V of the neocortex are glutamate, aspartate, and to a small extent GABA (Jones, 1986; Barbarisi et al., 1987; Conti et al., 1988b; Giuffrida and Rustioni, 1989; Tsumoto, 1990; Conti and Manzoni, 1994). These long-distance projection neurons also express ionotropic receptors, which include the $\mathrm{GABA}_{\mathrm{A}}$ receptor (GABA-R) and the glutamate receptors that bind kainate (KA-R), AMPA (AMPA-R), and NMDA (NMDA-R) (Huntley et al., 1993; Vickers et al., 1993; Brose et al., 1994; Currie et al., 1994; Van Eden et al., 1995; Ozawa et al., 1998; Weiss et al., 1998). When this stereotypic neurotransmitter/receptor expression is disrupted, neuronal dysfunction results, as evidenced by multiple disease states, including epilepsy, ischemia, neurodegeneration, and psychiatric disease (Faingold et al., 1988; Baker et al., 1990; Lummis et al., 1990; Fink et al., 1994; Benes, 1995; Olney and Farber, 1995; Rogers et al., 1996; Shaw and Ince, 1997; Loscher, 1998; Malizia et al., 1998; Qu et al., 1998; Zhang et al., 1998).

We have previously shown that transplanted neuroblasts and multipotent precursors can migrate and differentiate toward the replacement of degenerating neurons, when introduced to adult mouse cortex re-expressing developmental signals. These experiments used an approach of targeted degeneration of CPNs (Macklis, 1993; Madison and Macklis, 1993), which induces upregulation of intercellular developmental signal molecules (Wang et al., 1998). Transplanted neuroblasts respond to these signals and undergo migration specifically into layers undergoing degeneration of CPNs, followed by directed differentiation into pyramidal neurons, 
Targeted Neurodegeneration and Transplantation of Embryonic Neurons

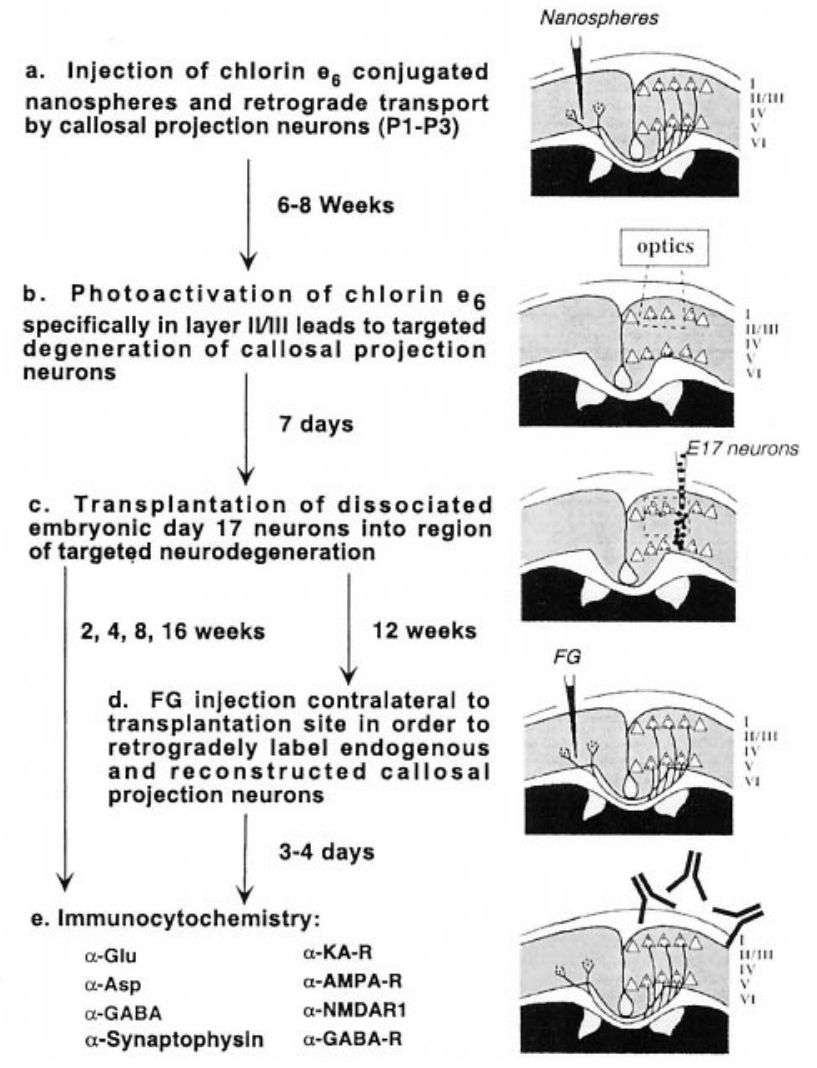

\section{Control and Comparison Studies}
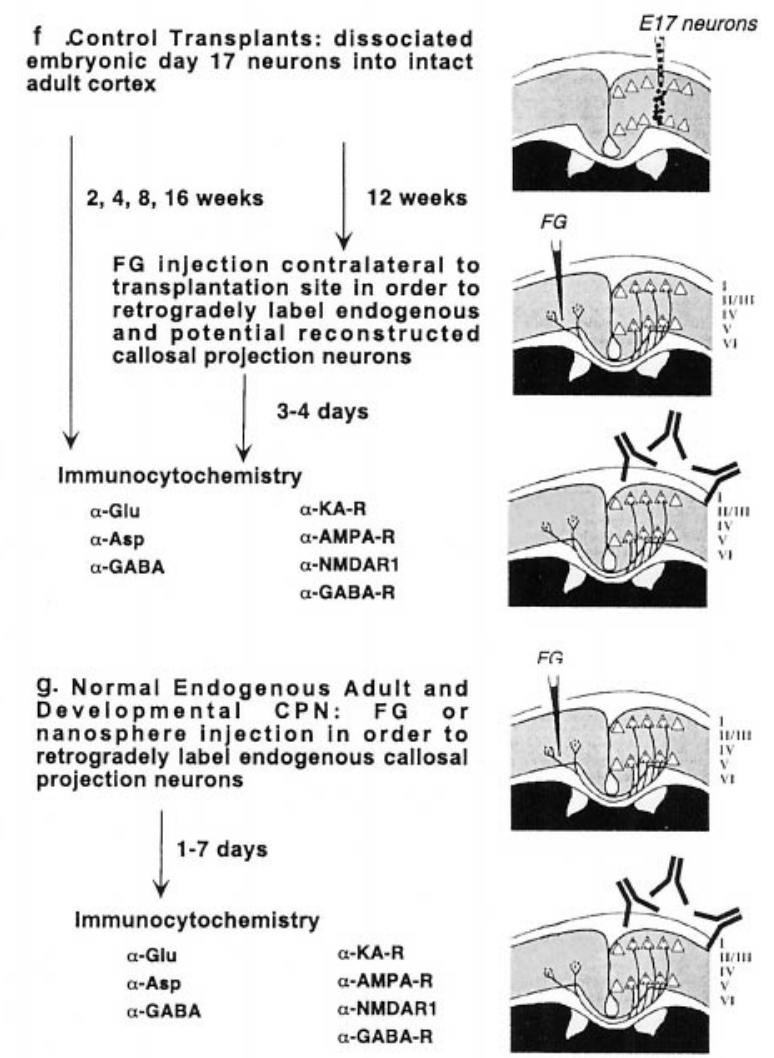

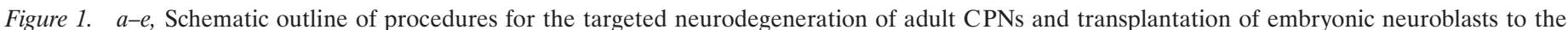

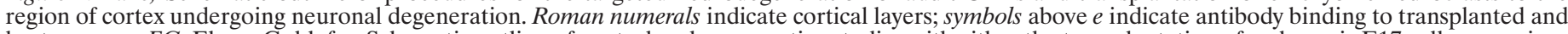

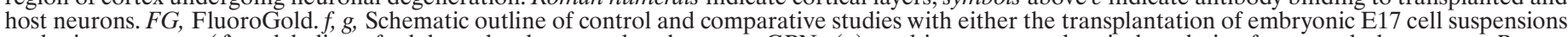

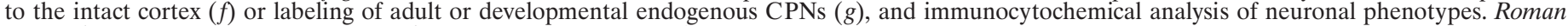
numerals indicate cortical layers; symbols above bottom panels of $f$ and $g$ indicate antibody binding to transplanted and host neurons.

and extension of axons across the corpus callosum to correct targets in the contralateral hemisphere (Macklis, 1993; Sheen and Macklis, 1995; Hernit-Grant and Macklis, 1996; Leavitt et al., 1999). The extent of the precision and fidelity of phenotypic differentiation by donor neuroblasts has not yet been fully explored.

Ultimately, toward functional reconstruction of complex circuitry within the neocortex, it will be crucial to determine whether transplanted neuroblasts not only have the appropriate morphology and anatomic connectivity to replace degenerating CPNs, but also have the capacity to communicate correctly with host neurons. Because neurotransmitters and their receptors are essential for synaptic processing, and distinct classes of neurons express stereotypic patterns of both, expression of CPN-specific neurotransmitters and their receptors are critical indicators of functional maturity of transplanted neuroblasts.

The current experiments assessed the neurotransmitter and receptor expression by transplanted neuroblasts, following directed differentiation and anatomic integration in adult mouse cortex in which selective death of CPNs was induced. In particular we determined: (1) whether transplanted neuroblasts differentiate and express the correct complement of neurotransmitters and their receptors in numbers appropriate for mature endogenous adult CPNs (compared with no or very few embryonic donor cells expressing these same neurotransmitters and receptors at the time of transplantation); and (2) the time course of this differentiation by donor neuroblasts, in comparison to the normal development of endogenous CPNs.

\section{MATERIALS AND METHODS}

This study is based on data from $n=104$ mice and $n=33,547$ analyzed neurons. C57B/J6 adult male and female mice were used according to an institutionally approved protocol. Fifty-nine mice were recipients of dissociated embryonic cells. Of these, 40 mice received transplants into neocortex undergoing targeted neural degeneration $(n=7$ or 8 per group examined at each time point), and the other 19 mice were used as age-matched controls receiving transplants into intact neocortex $(n=3$ or 4 per group). Six separate embryonic dissections were used, with each dissection containing cells from five to eight embryos. Endogenous adult CPNs were analyzed in 22 8- to 16-week-old mice. Developmental CPNs were assessed using 23 mice in the age range between embryonic day 17 (E17) and postnatal day 31 (P31) ( $n=3$ or 4 per group).

Targeted neuronal degeneration. Details of chlorin $e_{6}$ injection and exposure to long-wavelength laser light have been previously described (Macklis, 1993; Madison and Macklis, 1993; Sheen and Macklis, 1995) (Fig. 1). In summary, 2- to 4-d-old mouse pups were anesthetized by hypothermia. Glass micropipettes with tip diameters of $30-60 \mu \mathrm{m}$ were used to introduce fluorescein latex nanospheres (Lumafluor) conjugated to chlorin $e_{6}$ into the left primary somatosensory cortex (S1), using bregma and the coronal suture as landmarks. Nanospheres were microinjected at depths between $150 \mu \mathrm{m}$ and the surface, at 11 sites spaced evenly throughout $\mathrm{S} 1$ cortex, depositing $230 \mathrm{nl}$ total volume to the hemisphere. The pups were then returned to their dams. During the following days, chlorin $e_{6}$ conjugated nanospheres were retrogradely transported across the corpus callosum to the contralateral hemisphere (Fig. 1a) (Macklis, 1993; Madison and Macklis, 1993; Sheen and Macklis, 1995).

At the age of 6-8 weeks, mice were deeply anesthetized with Avertin $(0.02 \mathrm{ml} / \mathrm{gm})$. A small craniotomy $\sim 2.5 \times 2.5 \mathrm{~mm}$ was created above the noninjected hemisphere. The somatosensory cortex was then exposed, through intact dura, to light from a continuous wave $674 \mathrm{~nm}$ near-infrared laser with custom-collimating optics. This light exposure initiated the selective degeneration of CPNs mainly in layer II/III and to a smaller extent in layer V, over the following 1-2 weeks (Fig. 1b) (Macklis, 1993; Madison and Macklis, 1993; Sheen and Macklis, 1994).

Transplantation of embryonic cell suspensions. Transplants of dissociated E17 embryonic somatosensory cortical cells were performed 1 week after initiation of neuronal death. Timed E17 pregnant C57B/6J mice were terminally anesthetized, and embryos were removed. The developing S1 region from each cortex was dissected out and placed in dissection medium, which was comprised of: buffer, supplemented with $0.36 \%$ glucose, 
$0.8 \mathrm{~mm}$ magnesium kynurenate, $50 \mu \mathrm{m}$ APV, $50 \mathrm{U} / \mathrm{ml}$ penicillin, and 50 $\mu \mathrm{g} / \mathrm{ml}$ streptomycin. Tissue pieces underwent enzymatic treatment with $100 \mathrm{U}$ of papain for $30 \mathrm{~min}$ at $37^{\circ} \mathrm{C}$, before mechanical trituration with a 1 $\mathrm{ml}$ plastic Falcon pipette.

Cell suspensions were labeled with the lipophilic dye PKH 26 red (Sigma, St. Louis, MO) and custom-synthesized latex nanospheres containing rhodamine, which label neurons selectively (Madison et al., 1990; Macklis, 1993; Sheen and Macklis, 1995). PKH 26 initially localizes to the membrane, outlining cell somata and processes, and is later concentrated in lysosomes (Honig and Hume, 1989; Ashley et al., 1993). The neuronally incorporated nanospheres are also eventually concentrated in lysosomes, and persist in neurons indefinitely (Macklis, 1993; Sheen and Macklis, 1995). Labeled suspensions containing embryonic neuroblasts (approximate density of $5 \times 10^{7} \mathrm{cells} / \mathrm{ml}$ ) were transplanted to regions of adult S1 cortex undergoing targeted neuronal degeneration. Injection tracks spanned layers II/III through V. Micropipettes were used to introduce 50 $\mathrm{nl}$ of donor cells at intervals of $50 \mu \mathrm{m}$, from a depth of $500-100 \mu \mathrm{m}$ (total $300 \mathrm{nl}$ ). Each mouse received five to eight injections, spaced evenly in S1 cortex (Fig. 1c), with $\sim 100,000$ total cells injected per animal. Control transplants were performed in the same manner into age-matched intact adult mice.

FluoroGold injections into transplant recipients. Twelve weeks after transplantation, FluoroGold (FG; Fluorochrome) was injected into the contralateral cortex of transplanted mice [either experimental mice that had received chlorin $e_{6}$ and laser exposure (Fig. $1 d$ ) or previously intact adult controls (Fig. 1f)] to retrogradely label neurons extending axons to the contralateral hemisphere. A craniotomy $\sim 2.5 \times 2.5 \mathrm{~mm}$ was created above the S1 cortex contralateral to the transplanted region, and micropipettes were used to deliver $60 \mathrm{nl}$ of FG (a 2-3\% solution in distilled water) in a grid of 11 sites, placed at intervals of $50 \mu \mathrm{m}$, from a depth of 500-100 $\mu \mathrm{m}$. Four days were allowed for transport to the cell somata in the contralateral hemisphere.

Retrograde labeling of developmental and adult normal endogenous CPNs. A suspension of nanospheres containing fluorescein (Lumafluor) or FG solution was microinjected into the left $\mathrm{S} 1$, and we allowed 1-6 d for transport to the contralateral hemisphere for labeling of endogenous CPNs (Fig. 1g). FG was used whenever possible, because it best delineates neuronal morphology and allows distinction of cell somata. Because of the diff usion properties of FG, it was difficult to localize the solution consistently to cortex in younger mice. Therefore, younger mice received nanosphere injections, which could be precisely localized to cortex but would also allow good distinction of cell somata. The following parameters were used, according to animal age. On the day of birth (P0) and on P2, mice received $30 \mathrm{nl}$ of nanospheres, from a depth of $150 \mu \mathrm{m}$ to the surface, at six separate injection sites. They were perfused after $24 \mathrm{hr}$, at P1 and P3, respectively. $\mathrm{P} 3$ mice received $30 \mathrm{nl}$ of nanospheres, from a depth of 150 $\mu \mathrm{m}$ to the surface, at 11 separate injection sites and were perfused at P7 and P10. P10 mice received $8 \mathrm{nl}$ of FG, from a depth of $50 \mu \mathrm{m}$ to the upper layers of cortex, at eight separate injection sites, and were perfused at P14. Eight- to 16-week-old mice were used for adult CPN studies. Each received $60 \mathrm{nl}$ of FG in a grid of 11 sites in S1 cortex. At each site, injections were made at intervals of $50 \mu \mathrm{m}$, from a depth of 500-100 $\mu \mathrm{m}$. Mice were perfused $4 \mathrm{~d}$ after injection.

Tissue preparation. Mice were terminally anesthetized with Avertin $(0.04$ $\mathrm{cc} / \mathrm{gm})$ and transcardially perfused with $10 \mathrm{U} / \mathrm{ml}$ heparin in $0.9 \% \mathrm{NaCl}$, followed by $4 \%$ paraformaldehyde and $0.4 \%$ glutaraldehyde. Brains were post-fixed in the same solution for $24-41 \mathrm{hr}$. Series of $30 \mu \mathrm{m}$ coronal sections were obtained with a Vibratome (Technical Products International, O'Fallon, MO) and stored in PBS at $4^{\circ} \mathrm{C}$.

Immunocytochemistry. Sets of 9-11 sections (distributed evenly throughout anterior and posterior regions) were obtained from each mouse for immunocytochemistry (Fig. 1e). Free-floating sections were incubated with a blocking solution of $5 \%$ bovine serum albumin, $3 \%$ goat serum, and $0.5 \%$ Tween 20 for $2 \mathrm{hr}$. Samples were then incubated with the primary antibody diluted in blocking solution for 17-19 hr. The following primary antibodies were used at the following dilutions: (1) anti-glutamate IgG (1:500; Incstar, Stillwater, MN; mouse monoclonal); (2) anti-aspartate IgG (1:500; Sigma; rabbit polyclonal); (3) anti-GABA IgG (1:500; Incstar; rabbit polyclonal); (4) anti-glutamate receptor 5, 6, and 7 IgM (KA-R) (1:250; PharMingen, San Diego, CA; mouse monoclonal); (5) anti-NMDA-R1 IgG 2a (1:250; PharMingen; mouse monoclonal); (6) anti-glutamate receptor $2 / 3 \mathrm{IgG}$ (AMPA-R) (1:125; Oncogene; rabbit polyclonal); (7) anti-GABA receptor $\beta$ chain IgG $1(10 \mu \mathrm{g} / \mathrm{ml}$; Boehringer Mannheim, Indianapolis, IN; mouse monoclonal); and (8) anti-synaptophysin IgG $(20 \mu \mathrm{g} / \mathrm{ml}$; Boehringer Mannheim; mouse monoclonal). Samples with omission of primary antibody were also included as negative controls. Sections were rinsed four times with PBS and incubated with the matching secondary antibody for 2 $\mathrm{hr}$. The following secondary antibodies were used at the following dilutions: (1) anti-mouse IgG Cy3 (1:500; Jackson ImmunoResearch, West Grove, PA; goat polyclonal); (2) anti-rabbit IgG Alexa 488 (1:250; Molecular Probes, Eugene, OR; goat polyclonal); (3) anti-mouse IgG rhodamine (1:100; Boehringer Mannheim; goat polyclonal); and (4) anti-rabbit IgG FITC (1:100; Sigma; goat polyclonal). Sections were then rinsed four times with PBS. All steps were performed at $4^{\circ} \mathrm{C}$. The sections were then mounted and coverslipped with xylene-based Fluoromount or aqueousbased Fluoromount G (Electron Microscopy Sciences).

Analysis of cellular phenotypes. Neuronal counts were performed with a
$100 \times$ high numerical aperture objective on a Zeiss microscope equipped with epifluorescence. The following custom excitation and emission filters were used for visualization of fluorescent labeling to eliminate nonspecific fluorescence: (1) excitation 350-380, barrier >380 (FG); (2) excitation 450-490, barrier 510-540 (Alexa 488, FITC); and (3) excitation 538-553, barrier 590-620 (Cy3, rhodamine).

Immunolabeling was considered positive by criteria defined a priori: (1) if the signal was substantially and distinctly above background, and (2) if the signal was distinctly above the negative omission of primary antibody controls. Furthermore, the established criteria were that neurotransmitter immunofluorescence was classified as positive only if staining was homogenous throughout the cytoplasm, and receptor staining was considered positive only if staining was uniform throughout the cell membrane. To be considered double-labeled, morphology as delineated by FG and fluorescent secondary antibody had to be similar. Rare indeterminately labeled neurons were not included in the analysis.

Analysis of transplanted embryonic neurons. At 2, 4, 8, 12, and 16 weeks after transplantation, mice were perfused for immunocytochemical analysis. In individual series of sections, donor-derived neurons were identified, and their position relative to the transplantation site was determined. Only those neurons that migrated $>50 \mu \mathrm{m}$ from the injection site into layers II/III and V of somatosensory cortex were included in the analysis. This criterion was derived from previous studies indicating that the subpopulation of transplanted neuroblasts that actively migrate from the implantation site differentiate into mature neurons and extend axons across the corpus callosum to the contralateral cortex (Sheen and Macklis, 1995; Hernit-Grant and Macklis, 1996). Typically, neurons had migrated $100-200 \mu \mathrm{m}$ from the site of injection.

In addition, only neurons that had sufficient PKH 26 and nanosphere labeling to delineate $>50 \%$ of the cell circumference were included, to be certain of the position of the neuronal somata. Using these parameters, a total of 14,691 donor-derived neurons were included in the analysis, $\sim 85$ neurons per animal, for each phenotype investigated.

Analysis of developmental and adult normal endogenous CPNs. Layer II/III and V of primary somatosensory cortex contralateral to nanosphere or FG injections were analyzed. In adult mice, the anterior boundary for $\mathrm{S} 1$ cortex was defined as $0.1 \mathrm{~mm}$ posterior to bregma, at the level of the midline crossing of the anterior commissure. The posterior boundary was defined as $1.6 \mathrm{~mm}$ posterior to bregma. Using these borders, 50 coronal sections $(30 \mu \mathrm{m})$ were obtained from each animal. Medial and lateral boundaries were 1.5 and $2.7 \mathrm{~mm}$ from the midline, respectively, providing approximately seven fields per section at $100 \times$ magnification. Four alternate fields were included in the analysis (first, third, fifth, and seventh).

Analogous parameters were used for developmental CPN studies. Medial and lateral boundaries, as measured from the midline were as follows: for P1 and P3 mice, 0.5 and $0.9 \mathrm{~mm}$; for P7 mice, 0.7 and $1.1 \mathrm{~mm}$; for P10 mice, 1.0 and $2.2 \mathrm{~mm}$; and for P14 mice, 1.2 and $2.6 \mathrm{~mm}$. For P1, P3, and P7 mice, three of five potential fields were counted at $100 \times$ magnification. For P10 and P14 mice, four of seven potential fields were included.

Only neurons that had sufficient FG or nanosphere labeling to delineate $>50 \%$ of the cell body circumference were included, to be certain of the positions of neuronal somata. These parameters allowed inclusion of 18,856 endogenous CPNs in the analysis. The results for endogenous CPNs were verified by independent observers, with high inter-observer reliability. Variability among counts of endogenous CPNs in different mice was low, with a SE of $1.2 \%$ around the mean

Image acquisition. Low-power $(10 \times, 25 \times)$ fluorescence micrographs were obtained with a cooled CCD digital camera (Optronics). High-power $(40 \times, 100 \times)$ images were obtained using a Noran laser confocal system on a Nikon Diaphot microscope equipped with both an argon-krypton laser (Omnichrome) and a UV argon laser (Coherent), with Intervision software. For two-dimensional (2-D) overlays, fluorescence images from rhodamine and fluoroscein excitation and emission spectra for one plane of tissue were combined, and a composite image was prepared. For collapsed two-dimensional overlays, 5-30 images separated by $0.5 \mu \mathrm{m}$ were acquired over $15 \mu \mathrm{m}$, and all images were stacked. Stacked fluorescence images from three rhodamine, fluoroscein, and FG excitation and emission spectra were combined, and composite images collapsed to a single plane were created using Adobe PhotoShop.

Statistical analysis and quantification of data. Statistical analysis was performed using the GLM procedure in the SAS software package (version 6.12; SAS Institute, Cary, NC). In all cases, two-way factorial ANOVA was used to determine the percentage of neurotransmitter-receptor expression over the time course of the experiment. Comparisons were made either between the donor neuroblasts transplanted to regions of targeted neuronal degeneration and endogenous CPNs or between the donor neuroblasts transplanted to regions of targeted neuronal degeneration and donor neuroblasts transplanted to intact adult cortex. Two-tailed values of $p<0.05$ were considered significant in the ANOVA models. In addition, ANOVA was used to establish whether the absolute number of neurons was significantly different between the number of surviving neurons in transplants to the adult mouse cortex undergoing targeted neuronal degeneration versus transplants to the intact adult mouse cortex.

After ANOVA, post hoc $t$ tests were used for more precise identification of significant differences between groups. In all cases, a Bonferroni adjustment was made to maintain the appropriate type I $\alpha$ level of significance, i.e., a conservative two-tailed $p<0.01$ was considered statistically signif- 
icant for time point comparisons. To test at which point the percentage of transplanted neuroblasts that expressed neurotransmitters or receptors was equivalent to those of adult CPNs, multiple comparisons were run at each of the five time points after transplantation, using Fisher's least significant difference (LSD) procedure.

Because of the significantly enhanced survival of neurons transplanted into experimental versus control cortices, the data were normalized for graphical representation. The overall mean survival of neurons in experimental cortices was $4.2 \times$ survival in control cortices. Therefore this value was used to normalize the percentage of neurons in control cortex expressing each phenotype to the total number of surviving neurons in experimental cortex.

\section{RESULTS}

Neuroblasts transplanted to adult neocortex undergoing targeted apoptotic neuronal degeneration (experimental cortex) developed the phenotype of mature CPNs with high precision. The percentage of donor-derived neurons expressing each of the neurotransmitters or receptors increased over time, in experimental cortex but not in intact neocortex (control cortex). These percentages approximated the percentages of adult endogenous CPN expression by 4-12 weeks after transplantation. This maturation was more protracted than that seen during normal development. During development, the percentage of endogenous CPNs expressing these neurotransmitters and receptors increases to become equivalent to adult CPNs by P3 to P10.

\section{Survival, migration, and differentiation of transplanted immature E17 neuroblasts}

By 2 weeks after transplantation into experimental cortex, E17 neuroblasts migrated specifically to lamina II/III and V. Most neurons were located in layers II/III with $\sim 20 \%$ of neurons located in layer $\mathrm{V}$. These donor-derived neurons were still present at 16 weeks after transplantation, indicating good, long-term survival of the transplanted neuroblasts. As previously reported, many donor neuroblasts, identified by $\mathrm{PKH} \mathrm{26/rhodamine} \mathrm{nanosphere} \mathrm{labeling,}$ developed morphologies typical of CPNs, including large pyramidal cell bodies with apical dendrites and basal axons (Macklis, 1993; Sheen and Macklis, 1995; Hernit-Grant and Macklis, 1996).

After control transplants to intact adult cortex that received neither chlorin $e_{6}$ or laser exposure, substantially fewer neuroblasts migrated to layers II/III and V. The number of neurons present in the controls was significantly lower than the number of neurons in experimental mice at all time points observed. The overall mean number of surviving neurons at any time point was $559.6 \pm 148.6$ in experimental cortex versus $127.7 \pm 67.7$ in intact control cortex, an overall average of 4.2 times greater neuroblast survival in experimental versus control cortex $(p<0.005)$.

\section{Formation of callosal projections}

Quantification of the number of transplanted neurons that projected axons to the contralateral cortex was determined by injecting the retrograde label FluoroGold in the contralateral lamina II/III through $\mathrm{V}$, at 12 weeks after transplantation. Of a total of 156 donor-derived neurons counted, from four different experimental cortices, $23 \pm 6.8 \%$ were FluoroGold-labeled, indicating that their axons projected to the appropriate $\mathrm{S} 1$ region of contralateral cortex. Previous results (Hernit-Grant and Macklis, 1996) indicated that $\sim 21 \%$ of E17 neuroblasts make specific and appropriate contralateral projections at 12 weeks, with $0 \%$ projecting to the ipsilateral secondary somatosensory cortex, thalamus, or motor cortex (alternate targets of other populations of S1 cortical neurons, but inappropriate for neurons replacing CPNs previously targeted to undergo degeneration). No contralateral projections were observed from neurons transplanted to control cortex.

\section{Synapse formation}

The ability of donor neuroblasts in experimental cortex to differentiate into mature projection neurons and to express appropriate neurotransmitters and receptors suggests their competence to communicate with other neurons. To further investigate the level to which newly incorporated neurons integrated into cortical circuitry, we assessed the formation of synapses on donor-derived neurons
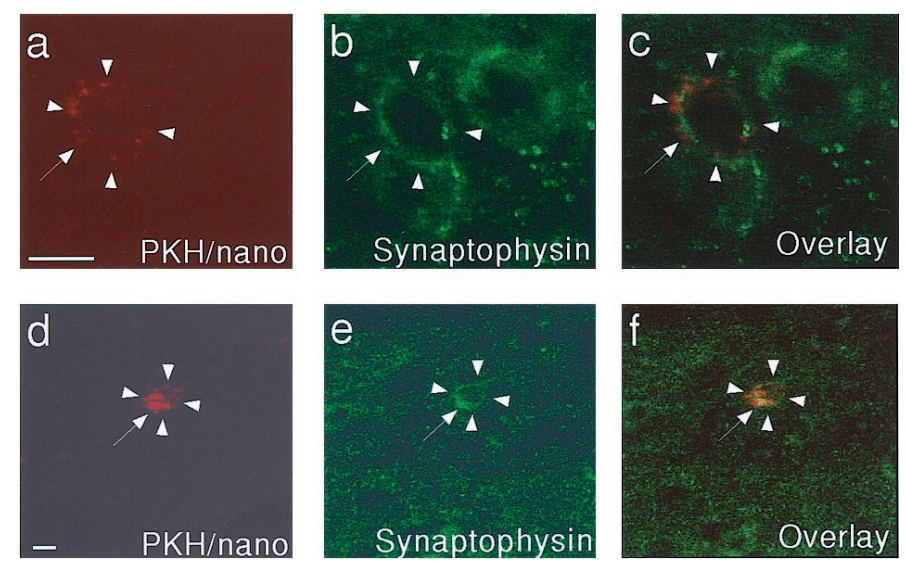

Figure 2. Synaptophysin immunoreactivity of terminals surrounding donor-derived neurons. $a$, High-power confocal microscope view of a donor-derived neuron 4 weeks after transplantation, in neocortex where selective neuronal degeneration has occurred. Arrowheads designate the donor-derived neuron, identified with PKH 26/rhodamine nanosphere labeling. Scale bar, $10 \mu \mathrm{m}$. $b$, Corresponding view of synaptophysin immunocytochemistry. Punctate staining resulting from concentration in synaptic vesicles is concentrated around the neuronal somata. $c$, Composite image of $a$ and $b$. $d$, Confocal microscope image of a donor-derived neuron 8 weeks after transplantation, in experimental neocortex. Arrowheads designate the neuron, identified with PKH 26/rhodamine nanosphere labeling. Scale bar, $10 \mu \mathrm{m}$. $e$, Corresponding view of synaptophysin immunocytochemistry. $f$, Composite image of $d$ and $e$.

with an antibody against synaptophysin, a presynaptic marker. Synaptophysin (also referred to as synaptophysin I) is a major integral membrane protein of small (30- to 50-nm-diameter) electron-translucent transmitter-containing synaptic vesicles in neurons. Its expression is tightly linked to the occurrence of these presynaptic vesicle types (Thiel, 1993; Eshkind and Leube, 1995). In addition, it is more homogeneously expressed in most nerve terminals than other synaptic vesicle markers, such as synaptoporin (Fykse et al., 1993). It has therefore been used in multiple studies as a marker of synaptic density, in cortex as well as other areas of the brain (Saito et al., 1994). We used immunocytochemistry directed against synaptophysin as a marker for synaptic input from other neurons onto the donor-derived neurons.

Many donor-derived neurons transplanted to experimental neocortex were found to have synaptophysin localized to presynaptic terminals surrounding the cell somata from 4 to 12 weeks after transplantation (Fig. 2). At 12 weeks after transplantation, $66 \pm 2 \%$ of donor-derived neurons in the experimental cortex colocalized synaptophysin. This provides evidence that other neurons formed synaptic inputs to the transplant-derived neurons, further indicating anatomical and functional reconnection of neuronal circuitry.

\section{Neurotransmitter and receptor expression}

Donor neuroblasts migrated into the appropriate layers II/III and $\mathrm{V}$ of the experimental mouse cortices and expressed appropriate neurotransmitters and their receptors (Figs. 3-9). This did not occur in controls. The percentage of donor-derived neurons expressing these appropriate neurotransmitters and receptors in experimental cortex showed a steady increase with time, from none or very few at the time of transplantation, to percentages of donor neurons equivalent to those of adult endogenous CPNs by 4-16 weeks after transplantation.

\section{Neurotransmitters: glutamate, aspartate, and $G A B A$}

Adult CPNs express the excitatory neurotransmitters glutamate and aspartate, and to a limited extent the inhibitory transmitter GABA. Therefore, we assessed whether and in what numbers donor-derived neurons express these neurotransmitters after transplantation into the adult mouse cortex undergoing targeted apoptotic neurodegeneration.

At the time of transplantation, E17 S1 cortical neuroblasts did 

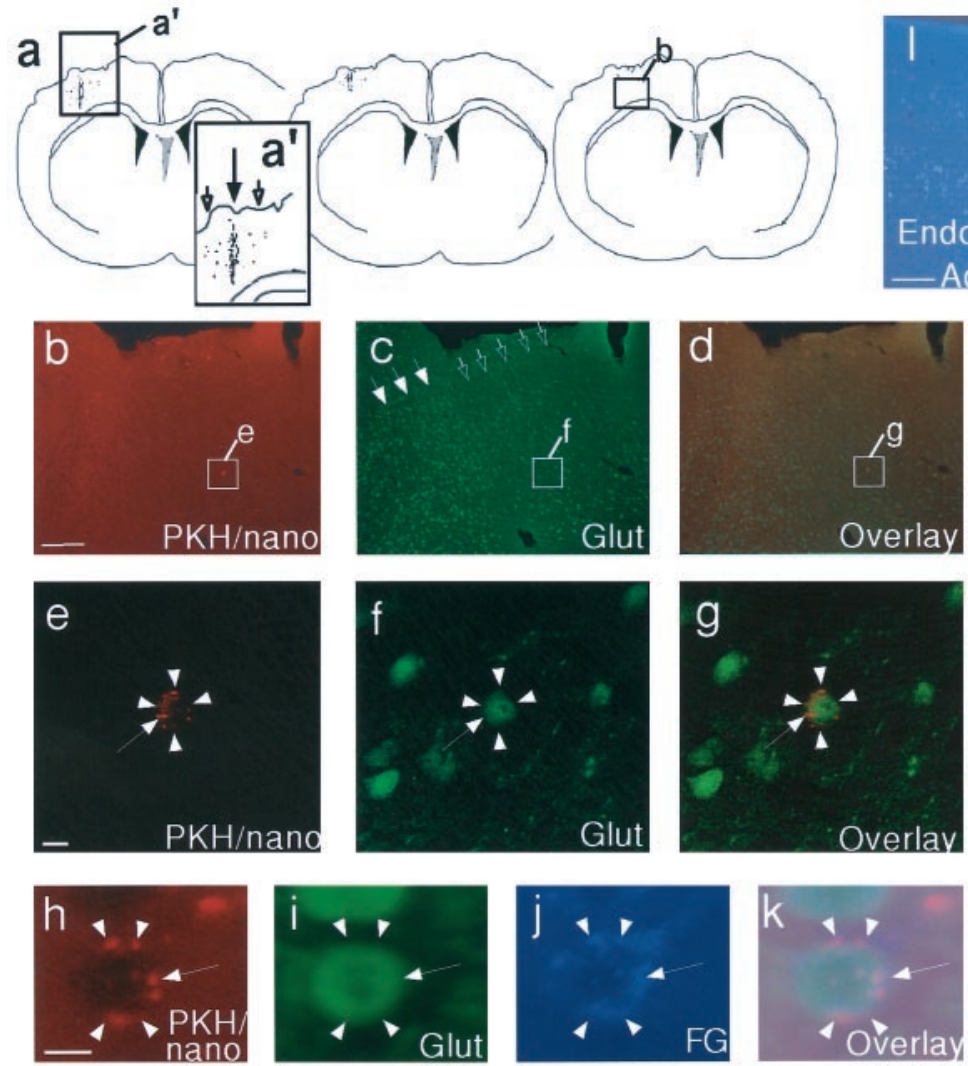
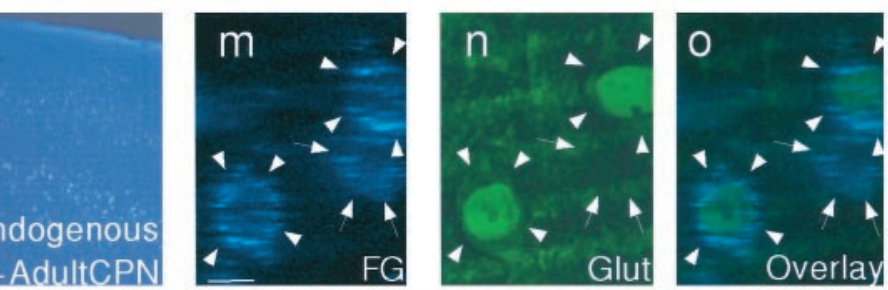

\section{P Glutamate Expression of Transplanted and Endogenous Neurons}

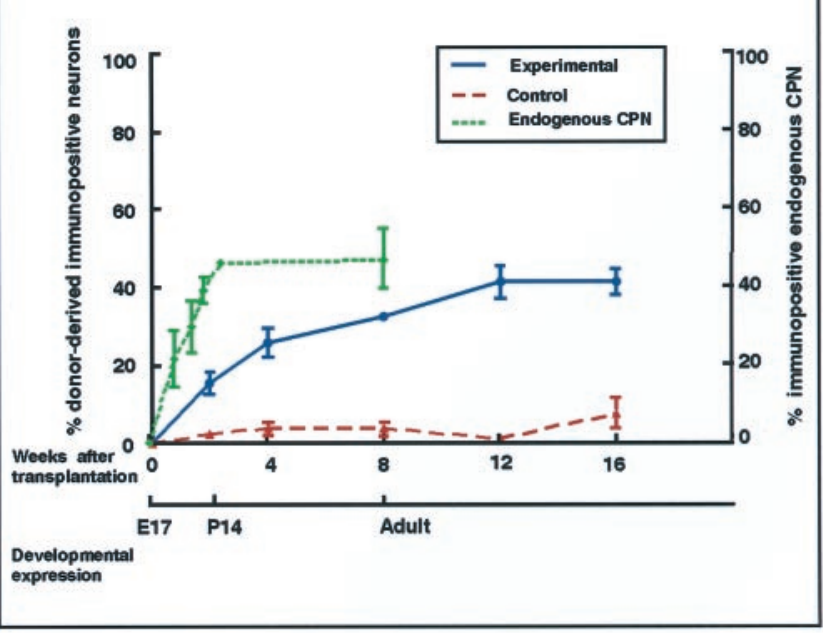

Figure 3. Glutamate expression of donor embryonic neuroblasts and normal endogenous CPNs. $a$, Camera lucida drawings of sequential $30 \mu \mathrm{m}$ coronal sections through and adjacent to a representative transplant site in regions of targeted neurodegeneration after 4 weeks. $a^{\prime}$, Area boxed in $a$. Solid arrow designates transplant site; open arrows designate adjacent areas of cellular migration. $b$, Low-power fluorescence micrograph of area boxed in $a$. Scale bar, $100 \mu \mathrm{m} . c$, Corresponding view of glutamate immunocytochemistry. Open arrows designate area of selective neuronal degeneration, showing dropout of glutamatergic neurons in regions exposed to long-wavelength laser light. Closed arrows designate the adjacent region that was unexposed to laser optics, where no neuronal death occurred. A higher density of glutamatergic neurons can be seen in layer II/III. $d$, Overlay of $b$ and $c$. $e-g$, High-power confocal microscope views of regions boxed in $b-d$. Arrowheads designate a donor-derived neuron, identified with PKH 26/rhodamine nanosphere labeling, which expresses glutamate. Scale bar, $10 \mu \mathrm{m}$. $h-k$. Superimposed high-power 2-D confocal images of a glutamatergic donor-derived neuron 12 weeks after transplantation that has been labeled with FG injected into the contralateral hemisphere. $h$ shows PKH 26/rhodamine nanosphere identification of the donor-derived neuron. Scale bar, $5 \mu \mathrm{m}$. $i$ shows glutamate immunoreactivity. $j$ shows FG retrograde labeling. $k$ is the composite image of $h-j . l$, Low-power fluorescence micrograph of endogenous adult CPNs retrogradely labeled by FG. Scale bar, $100 \mu \mathrm{m}$. $m$, High-power confocal microscope views of retrogradely labeled adult CPNs. Scale bar, $10 \mu \mathrm{m}$. $n$, Corresponding view of glutamate immunocytochemistry. $o$, Overlay of $m$ and $n$. Arrowheads designate CPNs that express glutamate. Arrows designate CPNs that do not express glutamate. $p$, Line graphs comparing glutamate expression of E17 neuroblasts transplanted to experimental cortex or intact control cortex and glutamate expression of normal developmental and adult endogenous CPNs. The $x$-axis (Weeks after transplantation) corresponds to transplanted neurons, and the $x$-axis (Developmental expression) corresponds to normal developmental and adult endogenous CPNs. The $y$-axis (\% donor-derived immunopositive neurons) corresponds to transplanted neurons (experimentals and controls), and the $y$-axis (\% immunopositive endogenous $C P N s$ ) corresponds to the normal developing and adult endogenous CPNs.

not express glutamate, but a small number did express aspartate ( $n=6$ mice) (Fig. $4 h)$ and GABA. It is not clear whether these aspartate-positive and GABA-positive neuroblasts represent the population of developing CPNs, because their projections are not yet fully formed at this stage of development, and therefore the neuroblasts could not be retrogradely labeled.

After transplantation into experimental cortices, the percentage of donor neuroblasts expressing glutamate (Fig. $3 a-k, p$ ), and aspartate (Fig. $4 a-c, l$ ), showed a significant increase over time. By 12 weeks after transplantation, the percentage of donor-derived neurons expressing glutamate did not differ significantly from adult CPNs $(41.5 \pm 4.1 \%$ in the transplanted neurons vs $46.5 \pm 8.0 \%$ in endogenous CPNs; Fisher's LSD: $p=0.36$ ) (Fig. $3 p$ ). For aspartate, the percentage of donor-derived neurons with expression matched that of adult CPNs by 8 weeks after transplantation $(35.2 \pm 4.3 \%$ of transplanted neurons vs $46.1 \pm 4.7 \%$ of endogenous CPNs) (Fig. $4 l$ ). This time course of development by transplanted neuroblasts was more protracted than that seen during development of normal endogenous CPNs. During normal development, the number of endogenous neurons expressing glutamate is equivalent to that seen in adult CPNs (Fig. $3 l-p$ ) by P10, and with aspartate, by P7 (Fig. $4 i-l$ ).

Immature neuroblasts transplanted to experimental cortex ex- pressed GABA in relatively low percentages throughout the time period analyzed (mean expression of $22.1 \pm 2.8 \%$ ). This was not significantly different from percentages of adult CPNs expressing GABA $(p>0.49$ at all time points measured) (Fig. $5 a-c, l)$. Our analysis showed that during development of endogenous CPNs, the percentages expressing GABA were initially high (at P1: $54.9 \pm$ $7.5 \%$ ), and declined over time to percentages typical of the adult CPN population (at 8 weeks: $20.3 \pm 1.24 \%$ ) (Fig. $5 h-l$ ). No similar initial peak of GABA expression was observed in the transplanted neuroblasts, although it may have occurred during the first 2 weeks after transplantation, before the first time point analyzed.

\section{Neurotransmitter expression in experimental versus control cortex}

A significantly higher percentage of neurons transplanted into experimental cortices expressed glutamate when compared to control cortices, at all times from 4 weeks after transplantation (Group effect: $p<0.001)$. Statistical analysis also showed that the percentage of donor neuroblasts expressing increased at a faster rate in experimental cortex compared with control cortex $(2.0$ vs $0.8 \%$ / week; $p=0.02$ ). Similarly, a significantly higher percentage of donor-derived neurons in experimental cortex expressed aspartate compared to those in control cortex, at all times examined (group 

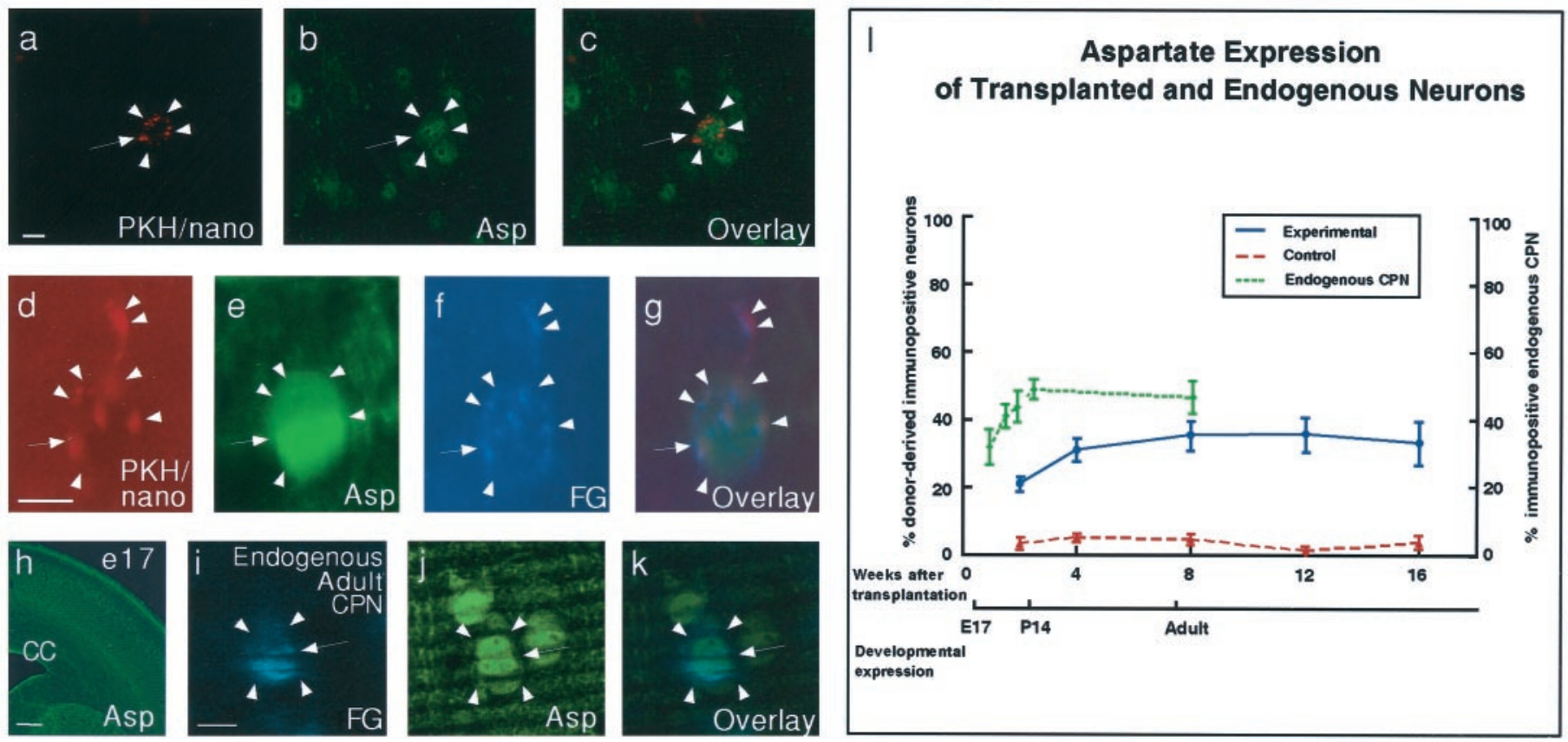

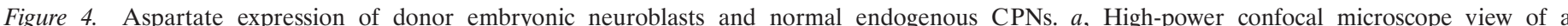

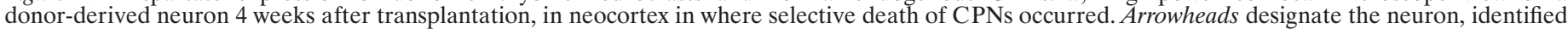

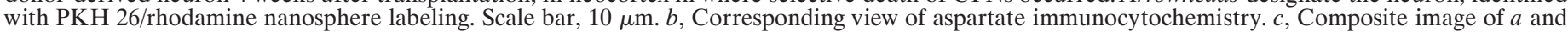

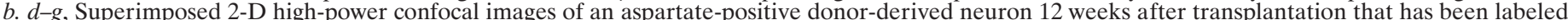

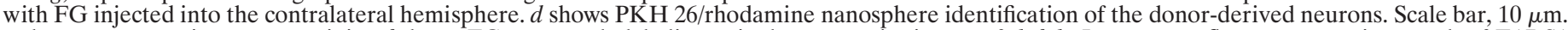

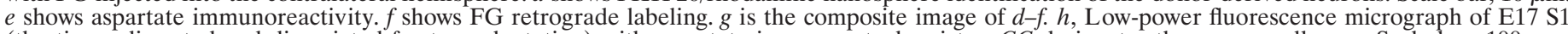

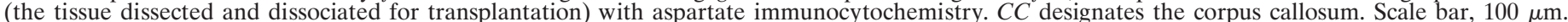

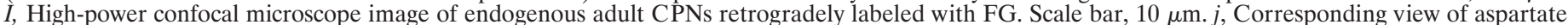

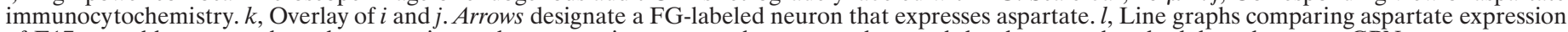
of E17 neuroblasts transplanted to experimental cortex or intact control cortex, and normal developmental and adult endogenous CPNs.

effect: $p<0.001)$. E17 neuroblasts transplanted to control intact neocortex expressed GABA in percentages similar to those in the normal adult CPN population; these percentages did not differ from those of donor neuroblasts transplanted to experimental cortex at any time (group $\times$ time effect; $p=0.7$ ).

However, at all times after transplantation, there were substantially more surviving transplanted neurons in experimental cortex than in control cortex. Therefore, when data were normalized to account for differences in survival, a substantially greater number of transplanted neurons in experimental cortex expressed glutamate (Fig. 3p), aspartate (Fig. 4l), and GABA (Fig. 5l), when compared to transplanted neurons in intact cortex.

\section{Donor-derived neurons that express appropriate neurotransmitters extend callosal projections}

By 12 weeks after transplantation to experimental cortices, retrograde tracing with FG identified glutamate-positive (Fig. 3h-k), aspartate-positive (Fig. 4d-g), and GABA-positive (Fig. 5d-g) donor-derived neurons that extended long-distance projections across the corpus callosum. Therefore, not only did the donorderived neurons express a functionally mature phenotype, but these same neurons formed long-distance and appropriate projections to target regions of the contralateral cortex.

\section{Neurotransmitter receptor expression: $G A B A-R, N M D A-R$, $A M P A-R$, and $K A-R$}

The majority of synaptic inputs to adult CPNs are inhibitory GABAergic inputs from surrounding interneurons of the cortex onto GABA receptors (GABA-R) on CPNs. Adult CPNs also possess receptors for the excitatory neurotransmitter glutamate: both the NMDA receptor (NMDA-R), and the non-NMDA receptors: the AMPA (AMPA-R) and kainate (KA-R) receptors. Therefore, we assessed whether and in what numbers donor- derived neurons to express these receptor subtypes after transplantation into the adult mouse cortex undergoing targeted apoptotic neurodegeneration.

At the time of transplantation into experimental cortex, E17 S1 cortical donor neuroblasts did not express GABA-R, NMDA-R, or AMPA-R. Very few E17 S1 cortical neuroblasts expressed the kainate receptor (KA-R).

The percentage of donor-derived neurons expressing GABA-R was initially low at 2 weeks after transplantation to experimental cortex and showed a steady increase over time, although percentages equivalent to those of adult CPNs were not fully achieved (Fig. $6 a-g, k$ ). At 16 weeks, $57.3 \pm 4.7 \%$ of neurons transplanted in regions of experimental cortex expressed GABA-R compared to $83.3 \pm 5.4 \%$ of endogenous adult CPNs (Fisher's LSD, $p=0.02$ ) (Fig. 6h-k).

Unlike GABA-R, the percentage of transplanted neurons that expressed each of the glutamate receptor subtypes NMDA-R, AMPA-R, and KA-R did reach levels equivalent to those of endogenous adult CPNs. The percentage of donor-derived neurons in experimental cortex that expressed NMDA-R at 12 weeks after transplantation was not significantly different from that of endogenous adult CPNs $(47.1 \pm 3.3 \%$ donor-derived neurons vs $52 \pm$ $4.7 \%$ adult CPNs; $p=0.38$ ) (Fig. 7). The percentage of donorderived neurons expressing either AMPA-R or KA-R was not significantly different from that of endogenous adult CPNs by 4 weeks after transplantation (for APMA-R: $p>0.4$, Fig. $8 a-g, k$; and for KA-R: $p=0.2$, Fig. $9 a-g, k)$.

The development of appropriate neurotransmitter receptors by donor-derived neurons in experimental cortex was more protracted than seen during normal development of endogenous CPNs. Although the increases in percentages of donor-derived neurons expressing AMPA-R and KA-R were the most rapid of all neurotransmitters and receptors examined (reaching adult values by 4 weeks after transplantation), this was still longer than the time 

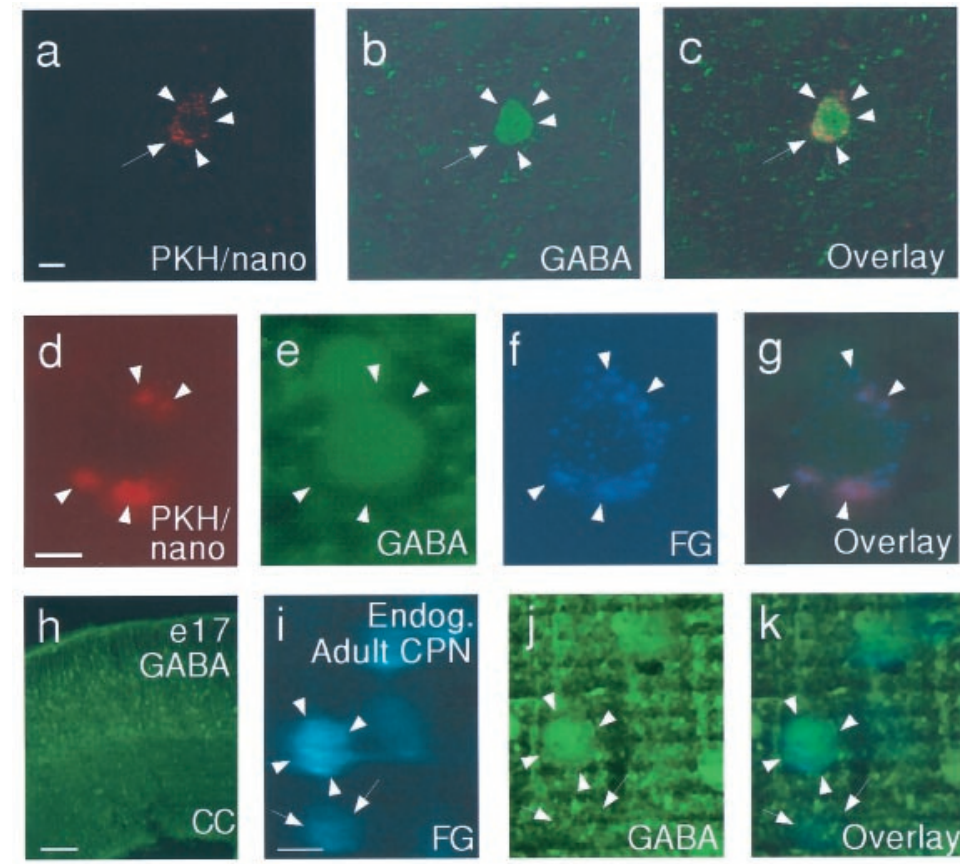
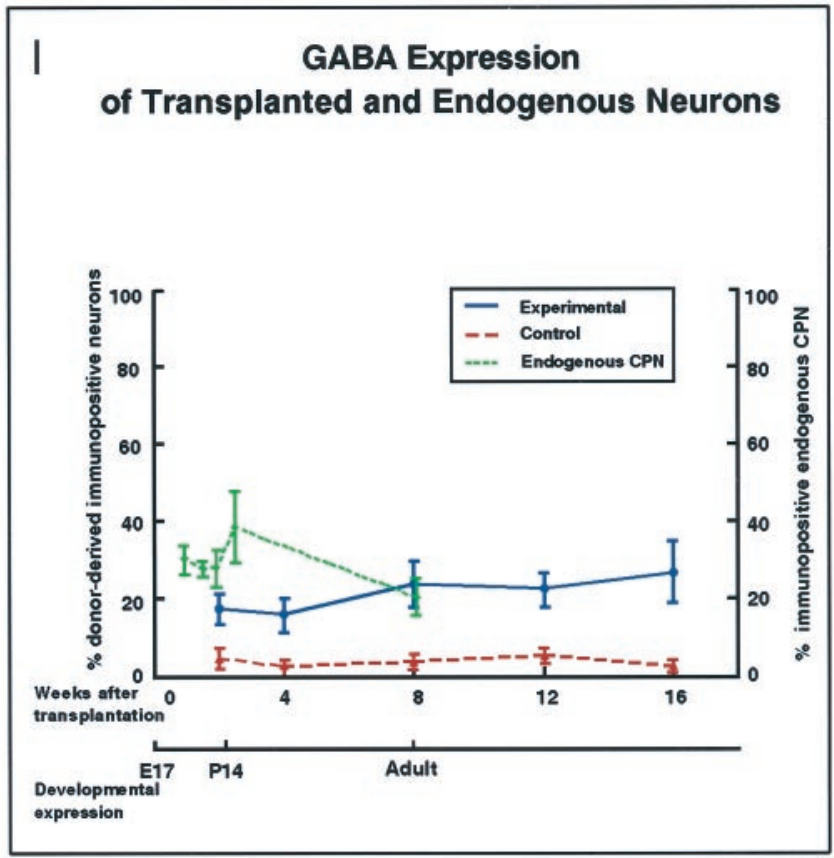

Figure 5. GABA expression of donor embryonic neuroblasts and normal endogenous CPNs. $a$, High-power confocal microscope view of a donor-derived neuron 4 weeks after transplantation, in neocortex where selective death of CPNs occurred. Arrowheads designate the donor-derived neuron, identified with PKH 26/rhodamine nanosphere labeling. The pyramidal cell body is easily distinguished. Scale bar, $10 \mu \mathrm{m}$. $b$, Corresponding view of GABA immunocytochemistry. $c$, Composite image of $a$ and $b . d-g$, Superimposed high-power 2-D confocal images of a GABAergic donor-derived neuron 12 weeks after transplantation, which has been labeled with FG injected into the contralateral hemisphere. $d$ shows PKH $26 /$ rhodamine nanosphere identification of the transplanted neuron. Scale bar, $5 \mu \mathrm{m}$. $e$ depicts GABA immunoreactivity. $f$ shows FG retrograde labeling. $g$ is the composite image of $d-f$. $h$, Low-power fluorescence micrograph of E17 S1 with GABA immunocytochemistry. Scale bar, $100 \mu$ m. $i$, High-power confocal microscope image of endogenous adult CPNs retrogradely labeled with FG. Scale bar, $10 \mu \mathrm{m}$. $j$, Corresponding view of GABA immunocytochemistry. $k$, Overlay of $i$ and $j$. Arrowheads designate a double-positive neuron or GABAergic CPNs; arrows designate a CPN that does not express GABA. $l$, Line graphs comparing GABA expression of E17 neuroblasts transplanted to experimental cortex or intact control cortex and normal developmental and adult endogenous CPNs.

required by normal developing CPNs. Endogenous CPNs express AMPA-R in numbers equivalent to adult CPNs $(56 \pm 5.3 \%)$ by postnatal day 7 (Fig. $8 h-k$ ) and KA-R in numbers equivalent to adult CPNs $(41.2 \pm 4.7 \%$ ) by postnatal day 3 (Fig. $9 h-k$ ).

\section{Receptor expression in experimental versus control cortex}

A significantly higher percentage of donor neuroblasts transplanted to experimental cortex expressed GABA-R compared to donor neuroblasts transplanted to the control intact cortex, at all time points from 4 weeks after transplantation. Similarly, a significantly higher percentage of donor neuroblasts transplanted to experimental cortex expressed NMDA-R or AMPA-R when compared to donor neuroblasts in control intact cortex (group effect: $p<0.001$ in each case). In contrast, there was no initial difference in the percentage of E17 neuroblasts that expressed KA-R between those transplanted to experimental neocortex or to control cortex. However, the increase in KA-R-positive neurons was more rapid in donor-derived neurons transplanted to experimental cortex when compared to controls (group $\times$ time effect: $p=0.01$ ) (Fig. $9 k$ ).

At all time points following transplantation, there were substantially more surviving neurons present in transplants to the experimental cortex than in transplants to the control intact cortex. Therefore, when data were normalized to account for differences in survival, transplants to experimental cortices contained a substantially greater number of GABA-R, NMDA-R, AMPA-R, and KA-R-positive neurons, compared to transplants to the control cortices.

Donor-derived neurons that express appropriate neurotransmitter receptors extend callosal projections

By 12 weeks after transplantation to experimental cortices, retrograde tracing with FG identified GABA-R-positive (Fig. 6d-g), NMDA-R-positive (Fig. 7d-g), AMPA-R-positive (Fig. 8d-g), and
KA-R-positive (Fig. 9d-g) donor-derived neurons that extended long-distance projections across the corpus callosum. Therefore, not only did the donor-derived neurons express the appropriate complement of receptors necessary for receiving synaptic input, but these same neurons formed long-distance projections to target regions of the contralateral cortex.

\section{DISCUSSION}

Here, we demonstrate for the first time that embryonic neuroblasts, transplanted to regions of neocortex undergoing targeted neuronal degeneration, express the appropriate neurotransmitters (glutamate, aspartate, GABA) and their receptors (KA-R, AMPA-R, and NMDA-R) at percentages similar to those of normal adult CPNs and GABA-R at a percentage approaching that of adult $\mathrm{CPNs}$. This expression of neurotransmitters and receptors, indicating an appropriate mature CPN phenotype, developed over a more protracted time period in transplanted neuroblasts than in normal endogenous developing CPNs. In addition, we confirm and extend previous results, showing that transplanted neurons also migrate into appropriate cortical lamina, extend long-distance axonal projections to appropriate targets in the contralateral cortex, and receive afferent synapses from other neurons. Both the survival of donor-derived neurons and their expression of neurotransmitters and receptors was significantly higher in donor neuroblasts transplanted in experimental neocortex than in neurons derived from donor neuroblasts transplanted to control intact neocortex. Taken together, these results demonstrate that donor neuroblasts respond to altered intercellular signals in the neocortex undergoing targeted neuronal degeneration and undergo directed differentiation under these conditions, developing with phenotypic fidelity to replace degenerating CPNs. 

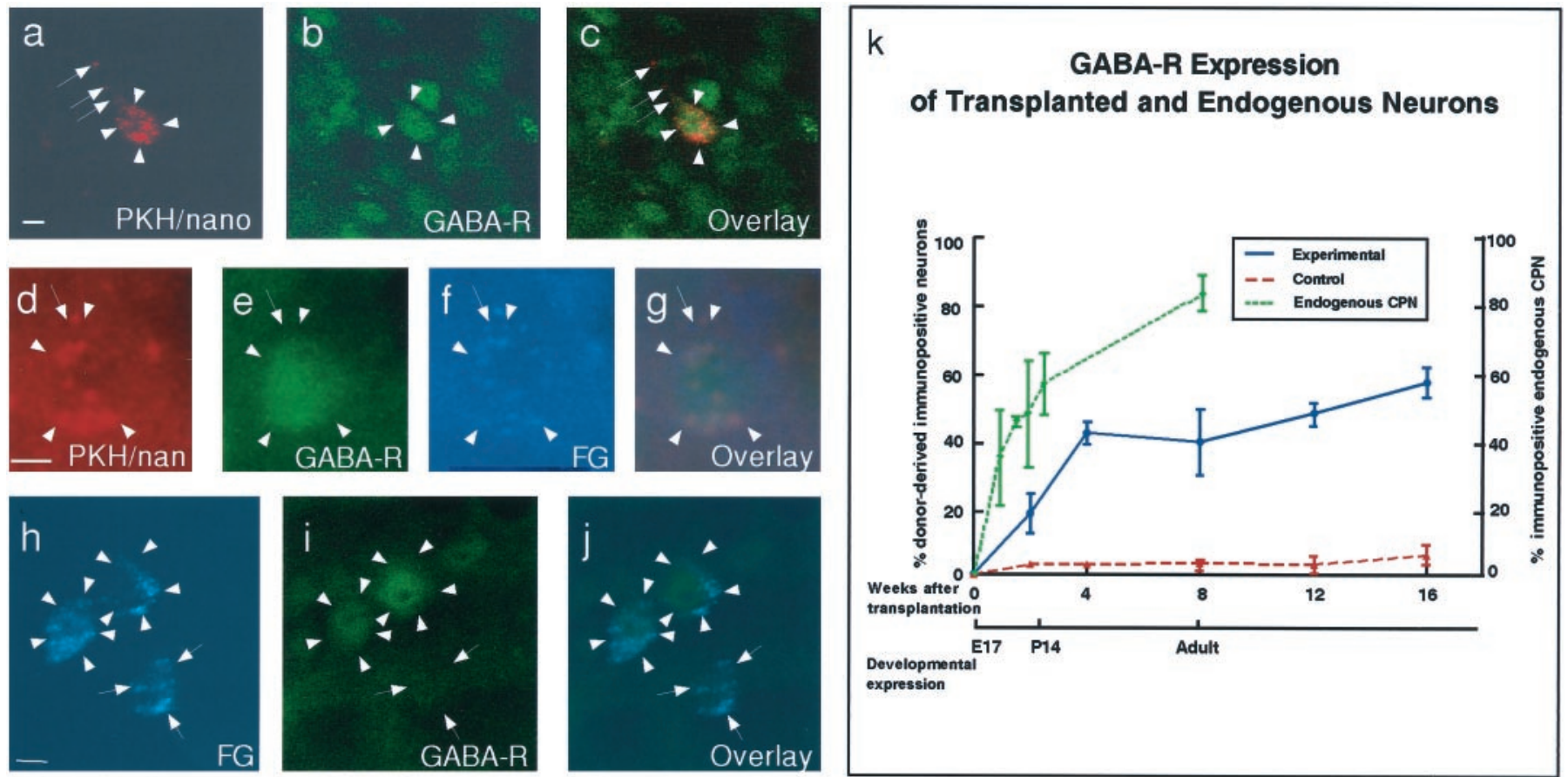

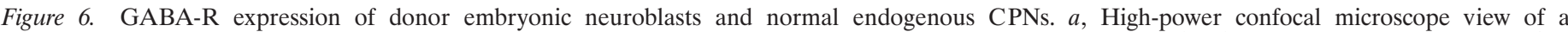

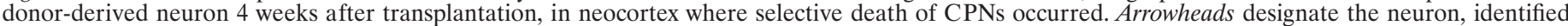

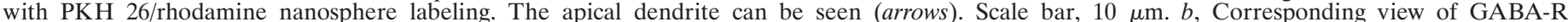

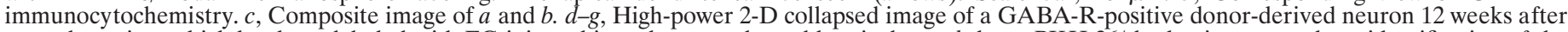

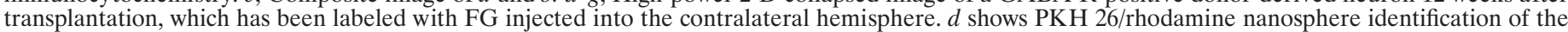

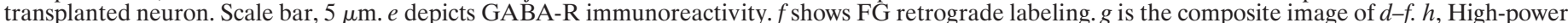

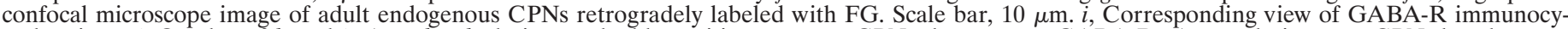

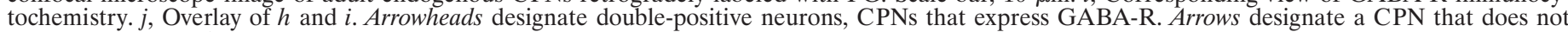

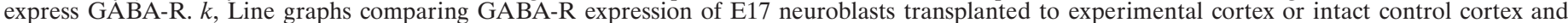
normal developmental and adult endogenous CPNs.

\section{Neuroblasts transplanted to regions of targeted neuronal degeneration in the adult cortex develop a mature CPN phenotype}

Here, we have shown for the first time that transplanted neuroblasts are capable of differentiating with high precision and fidelity to express a neurotransmitter and receptor phenotype that is appropriate for adult cortical projection neurons (Barbarisi et al., 1987; Conti et al., 1988a,b; Voigt et al., 1988; Dinopoulis et al., 1989; Giuffrida and Rustioni, 1989; Huntley et al., 1993; Vickers et al., 1993; Conti and Manzoni, 1994; Huntley et al., 1994; Gonchar et al., 1995). Many cortical transplantation studies to date have focused mainly on the introduction and maintenance of neuroblasts placed into pre-formed lesions of the neocortex, many of which show limited afferent connectivity from the host brain and extremely sparse efferent connectivity (Grabowski et al., 1992; Isacson and Sofroniew, 1992; Schulz et al., 1993; Sørensen et al., 1996). Previous results from our laboratory show that embryonic neuroblasts and neuronal precursors transplanted to regions of neocortex undergoing targeted neuronal degeneration undergo directed migration, differentiation to a neuronal phenotype, and extension of long-distance axonal projections to appropriate targets in the contralateral cortex (Macklis, 1993; Sheen and Macklis, 1995; HernitGrant and Macklis, 1996; Snyder et al., 1997; Leavitt et al., 1999). Using these same approaches, endogenous precursors can be activated in situ, undergo similarly directed migration, neuronal differentiation, long-distance axonal projection, and even behaviorally functional circuit restoration in adult songbirds and mice (Magavi et al., 2000; Scharff et al., 2000). Although other studies have explored neuronal differentiation (Stein and Mufson, 1987; Yirmiya et al., 1988; Valouskova and Galik, 1995) and expression of some phenotypic markers (Gonzalez and Sharp, 1987; Mufson et al., 1987; Jansen et al., 1997) by transplanted cortical tissue, none of these studies has investigated in detail the fidelity and precision with which transplanted neuroblasts undergo phenotypic differentiation required for high-level functionality. The development of a mature CPN phenotype in the studies reported here is also indicative of functional maturity, i.e., the ability of newly incorporated neurons to integrate and communicate in an appropriate manner with other neurons in the complex cortical circuitry.

This appropriate neurotransmitter and receptor expression provides further evidence that embryonic neuroblasts can differentiate toward replacement of CPNs in response to molecular signals upregulated during synchronous apoptosis of host CPNs. The current study demonstrates that these donor neuroblasts develop the appropriate intracellular machinery for interneuronal communication via synthesis of the correct neurotransmitter and receptor subunits. The percentages of these neurotransmitters and receptors increase from few or none at the time of transplantation to high percentages similar to those seen in normal adult CPNs.

\section{Transplanted neuroblasts receive afferent synapses}

The localization of synaptophysin, a presynaptic marker of mature synapses, to terminals surrounding the somata of transplantderived neurons, demonstrates that host neurons form synapses with the transplanted neuroblasts. The ability of donor neuroblasts to express appropriately the correct complement of neurotransmitters and their receptors further supports the conclusion that they are capable of forming synapses with other neurons. During normal development, increases in neurotransmitters and their receptors occur simultaneously with synaptogenesis (Langui et al., 1988; Lidow et al., 1991). Synaptic contacts potentially derive from endogenous local interneurons or contralateral CPNs or from other donor-derived neurons. Whether these synaptic connections are functional awaits further investigation. 

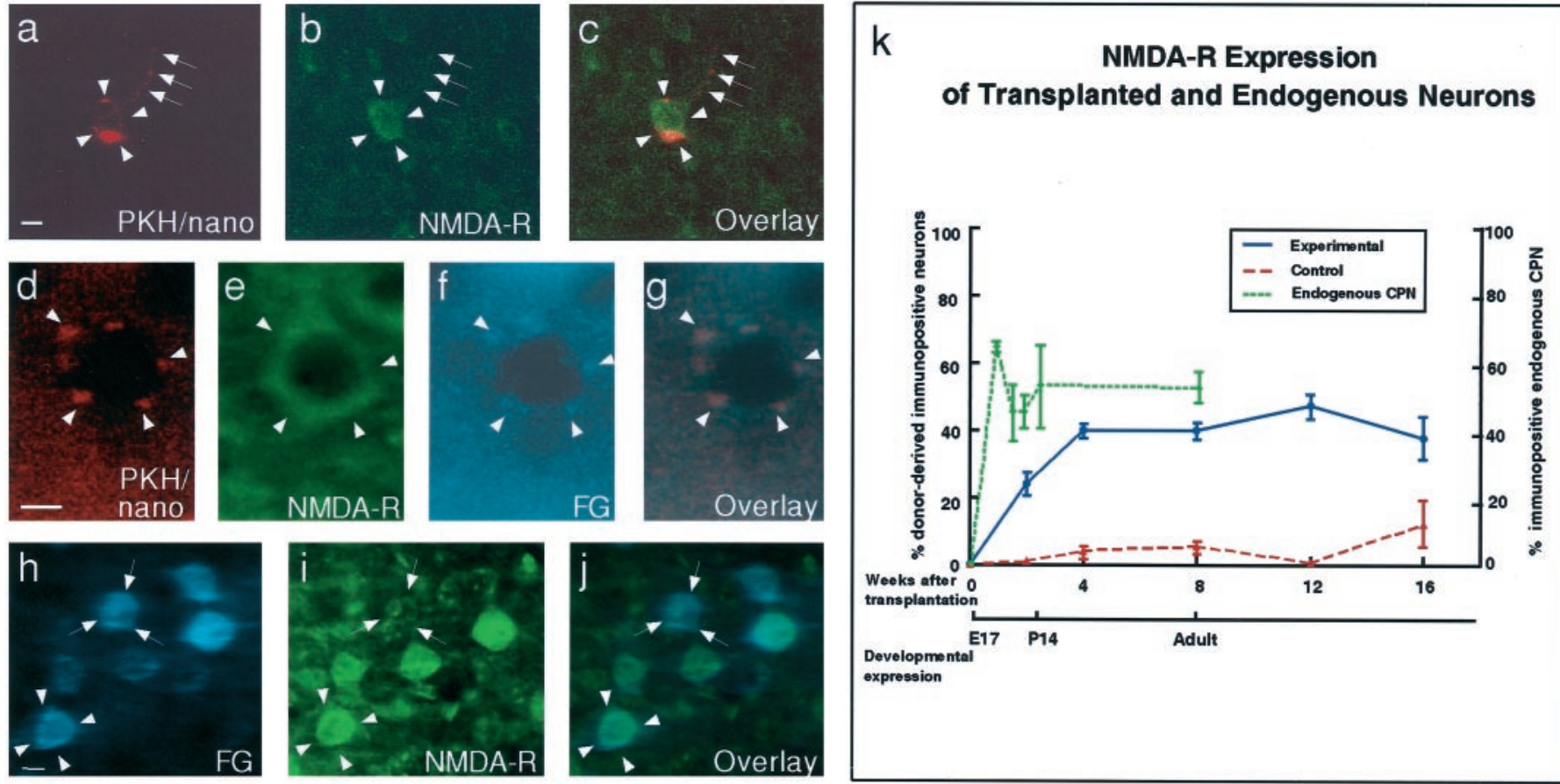

Figure 7. NMDA-R expression of donor embryonic neuroblasts and normal endogenous CPNs. $a$, High-power confocal microscope view of a donor-derived neuron 4 weeks after transplantation, in neocortex where selective death of CPNs occurred. Arrowheads designate the neuron, identified with PKH 26/rhodamine nanosphere labeling. The apical dendrite is well demarcated (arrows). Scale bar, $10 \mu \mathrm{m}$. $b$, Corresponding view of NMDA-R immunocytochemistry. $c$, Composite image of $a$ and $b . d-g$, High-power 2-D collapsed images of an NMDA-R-positive donor-derived neuron 12 weeks after transplantation, which has been labeled with FG injected into the contralateral hemisphere. $d$ shows PKH 26/rhodamine nanosphere identification of the transplanted neuron. Scale bar, $5 \mu \mathrm{m}$. $e$ depicts NMDA-R immunoreactivity. $f$ shows FG retrograde labeling. $g$ is the composite image of $d-f$. $h$, High-power confocal microscope images of adult endogenous CPNs retrogradely labeled with FG. Scale bar, $10 \mu \mathrm{m}$. $i$, Corresponding view of NMDA-R immunocytochemistry. $j$, Overlay of $h$ and $i$. Arrowheads designate a double-positive neuron or CPN that expresses NMDA-R. Arrows designate a CPN that does not express NMDA-R. $k$, Line graphs comparing NMDA-R expression of E17 neuroblasts transplanted to experimental cortex or intact control cortex and normal developmental and adult endogenous CPNs.

\section{Differentiation of transplanted neuroblasts to a mature CPN phenotype is influenced by both extrinsic and intrinsic factors}

The significant difference in neurotransmitter and receptor expression of donor neuroblasts transplanted to adult mouse cortex undergoing targeted neuronal degeneration versus control intact cortex shows that the immediate environment can strongly affect the phenotypic fate of developing neuroblasts. Multiple previous studies have also reported the expression of differential neurotransmitter and receptor properties by neurons, depending on neuronal surroundings (Clendening and Hume, 1990; Paschen et al., 1997), depolarization, specific neurotransmitters (Patterson, 1978), target tissue interactions (Landis, 1990), glial-neuronal communication (Poulter and Brown, 1999), hormones (McCauley and Gee, 1995; Zhang et al., 1999), and neurotrophins (Ernsberger and Rohrer, 1988; Iacovitti et al., 1989; Sieber-Blum, 1991).

Previous experiments have shown that during synchronous targeted degeneration of CPNs in the adult mouse cortex, there is local upregulation of a specific set of both known developmental and novel genes, now under investigation (Wang et al., 1998; T. A. S. Deuel, T. Chae, and J. D. Macklis, unpublished observations). The genes for brain-derived neurotrophic factor (BDNF), neurotrophin-4/5 (NT-4/5), and NT-3 are dramatically upregulated by adjacent interneurons (Wang et al., 1998). Neurotrophins are known to regulate neurotransmitter and receptor phenotype of neurons. For instance, NT-4/5 is known to increase GABA uptake or receptor expression in cultured cortical neurons (Widmer and Hefti, 1994). Similarly, BDNF is known to increase glutamate and GABA transmission, to increase GABA uptake, and to potentiate the effect of glutamate on NMDA receptors (Thoenen, 1995; Takei et al., 1997; Li et al., 1998; Pellegri et al., 1998; Sala et al., 1998; Pozzo-Miller et al., 1999). NT-4/5, BDNF, and other signaling molecules not yet identified may have thus partially determined the pattern of neurotransmitters and their receptors expressed by donor neuroblasts.
This study also supports the view that the intrinsic commitment of a neuroblast plays a significant role in its phenotypic maturation. Neurons transplanted to the intact cortex show expression of the same set of neurotransmitters and their receptors, although the percentage of neurotransmitter/receptor differentiation is lower than after transplantation to experimental cortex. It has been shown that neurons can maintain unique patterns of receptor expression in vitro, according to their anatomic origin in vivo (Koller et al., 1990; Gotz et al., 1995). In previous studies of transplantation to the adult mouse cortex undergoing targeted neuronal degeneration, E17 neuroblasts attained a mature morphology and formed appropriate connections with higher fidelity than younger E14 neuroblasts and noncommitted progenitors (Hernit-Grant et al., 1996; Sheen et al., 1999). Intrinsic mechanisms of lineage and commitment certainly play a major role in the specification of phenotype, but these can be strongly modulated by exogenous stimuli (Zhou and Bradford, 1997).

Neurotransmitters and their receptors themselves also play a role in development, their expression and activity affecting neuronal differentiation, dendritic and axonal outgrowth, and synaptogenesis (Lipton and Kater, 1989; Cherubini et al., 1991; Meier et al., 1991; Kennedy and Tessier-Lavigne, 1995; Behar et al., 1996; Retz et al., 1996; Levitt et al., 1997). Indeed, it has been shown that blockade of glutamate receptors at synapses in the rat S1 cortex disrupts the establishment of both topographic connectivity and columnar organization in the somatosensory cortex (Fox et al., 1996). In addition, neurotransmitters and receptors can influence the phenotype of other neurons, either acting alone (Davis and Murphy, 1994), or in concert with other molecules (Barde, 1990; Cohen-Cory et al., 1991; Favaron et al., 1993). It is therefore possible that the early expression of neurotransmitters and their receptors by some developing transplanted neuroblasts may have affected the differentiation of other nearby transplanted neuroblasts. This secondary influence could also provide an explanation 

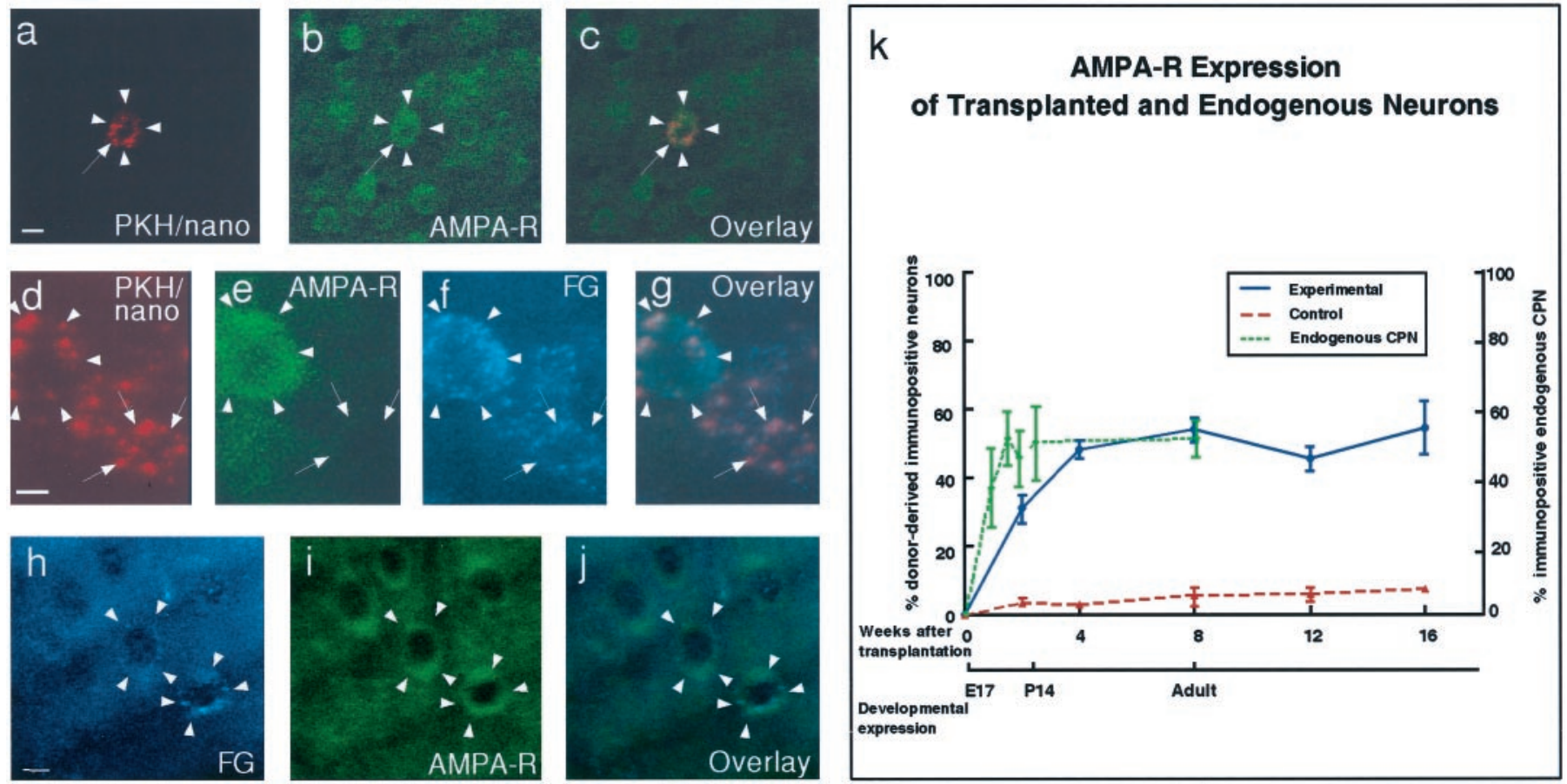

Figure 8. AMPA-R expression of donor embryonic neuroblasts and normal endogenous CPNs. $a$, High-power confocal microscope view of a donor-derived neuron 4 weeks after transplantation, in neocortex where selective death of CPNs occurred. Arrowheads designate the neuron, identified with PKH 26/rhodamine nanosphere labeling. Scale bar, $10 \mu \mathrm{m}$. $b$, Corresponding view of AMPA-R immunocytochemistry. $c$, Composite image of $a$ and $b . d-g$, Superimposed high-power 2-D confocal microscope images of donor-derived neurons 12 weeks after transplantation, which have been labeled with FG injected into the contralateral hemisphere. Arrowheads depict neurons that are AMPA-R-positive. Arrows designate a nonimmunoreactive cell. $d$ shows PKH 26/rhodamine nanosphere identification of the transplanted neuron. Scale bar, $5 \mu \mathrm{m}$. $e$ depicts AMPA-R immunoreactivity. $f$ shows FG retrograde labeling. $g$ is the composite image of $d-f$. $h$, High-power confocal microscope images of adult endogenous CPNs retrogradely labeled with FG. Scale bar, $10 \mu \mathrm{m}$. $i$, Corresponding view of AMPA-R immunocytochemistry. $j$, Overlay of $h$ and $i$. Arrowheads designate double-positive neurons or CPNs that express AMPA-R. $k$, Line graphs comparing AMPA-R expression of E17 neuroblasts transplanted to experimental cortex or intact control cortex and normal developmental and adult endogenous CPNs.

for the more protracted increase in the number of transplanted neuroblasts expressing appropriate neurotransmitters and their receptors over several weeks.

\section{Neurotransmitter and receptor development is more protracted in transplanted versus endogenous CPNs}

The percentage of donor-derived neurons that expressed neurotransmitters and their receptors in experimental cortex increased at a more protracted rate than seen in endogenous CPNs during normal corticogenesis. Typically, developing cortical neurons acquire their neurotransmitter and receptor phenotype within a few days to a few weeks of birth (Cobas et al., 1988; Erdo and Wolff, 1990; Shaw and Lanius, 1992; Micheva and Beaulieu, 1995; Oh et al., 1995; Arai et al., 1997; Gordon et al., 1996, 1997; Kimura and Baughman, 1997; Kiser et al., 1998). The slower rate of maturation of transplanted neuroblasts may result from a number of mechanisms. First, donor embryonic neuroblasts may simply require more time to express appropriate neurotransmitters and their receptors because of trauma associated with dissociation and transplantation, combined with placement in an environment that only partially recreates the environment present during corticogenesis. Second, it is theoretically possible but less likely that there may be two subpopulations of donor neuroblasts: one subpopulation expressing appropriate neurotransmitters and their receptors; and a second subpopulation that fails to integrate and establish connections, and subsequently dies over time. This later neuronal death would lead to a decrease in the total number of transplanted neurons and therefore a relative increase in the proportion of neurons expressing a particular transmitter or receptor. We did indeed observe a decrease in the total number of donor-derived neurons with time after transplantation. However, this may more likely be attributable to decreased identification of the donorderived neurons (because of lysosomal processing of the markers
PKH26 and rhodamine nanospheres), leading to underestimates of neuron survival, particularly at later survival times. A third mechanism may be the slow secondary influence of maturing donorderived neurons in the production of signals necessary for directed differentiation and maturation of other surrounding neuroblasts, as discussed above.

Donor-derived neurons transplanted to experimental neocortex began to express the appropriate complement of neurotransmitters and receptors by 2 weeks after transplantation. Increasing numbers of donor-derived neurons expressed each of the neurotransmitters/ receptors with comparable rates of progression over time. However, the time at which the percentage of donor-derived neurons expressing a particular phenotype became similar to the percentage in adult endogenous CPNs occurred variably between 4 and 12 weeks after transplantation. It is unknown whether these differences in rates of particular phenotype differentiation are significant. It is possible that the progression of expression of the neurotransmitters and neurotransmitter receptors investigated here reflects their normal developmental order of expression. The transplanted immature neuroblasts may have already initiated a program of progressive gene expression by the time of transplantation. It has previously been suggested that, during development, distinct classes of cortical projection neurons are already formed, before neuronal migration from the neuroepithelium to their specific lamina within the cortex (Koester and O'Leary, 1993). Other transplantation studies suggest that specification of corticocortical connections by cerebral grafts may be linked to the timing of neurogenesis, with postmitotic neurons adopting a pattern of connectivity consistent with them having already initiated a particular differentiation program (Barbe and Levitt, 1995). In that case, the local environment in the experimental mice might be especially supportive of the survival of these young neurons during their 

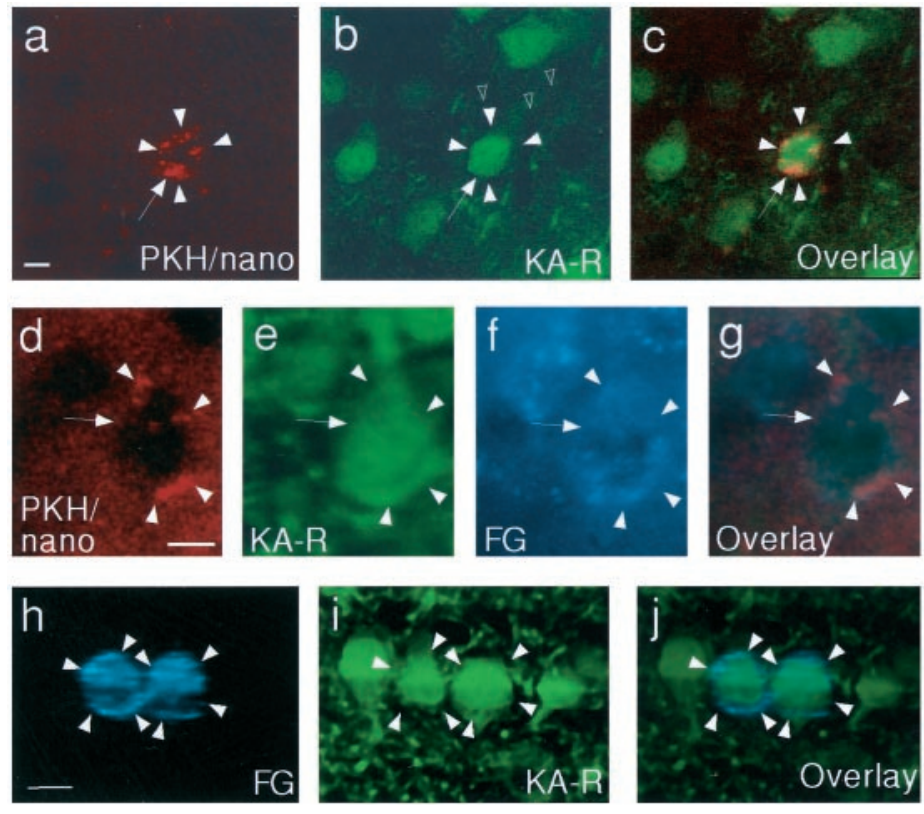

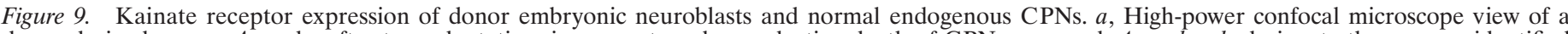

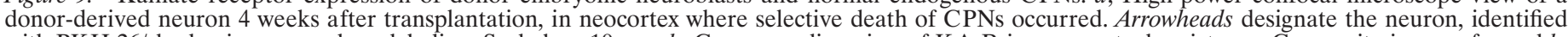

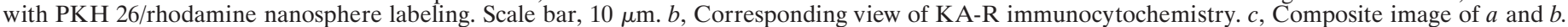

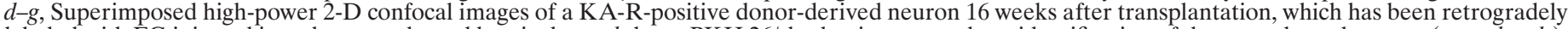

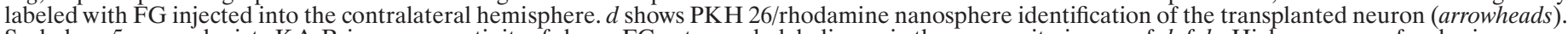

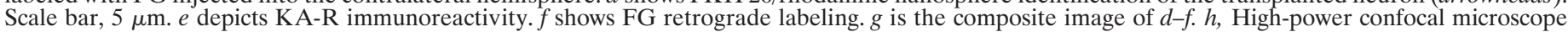

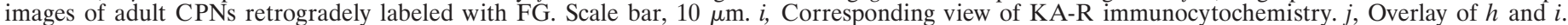

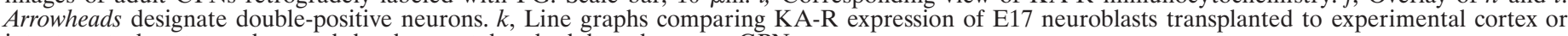
intact control cortex and normal developmental and adult endogenous CPNs.

differentiation. Differences in the rate of expression of individual neurotransmitters and receptors may be the result of the environment created by the targeted apoptotic degeneration of CPNs, which may preferentially favor the rapid differentiation of particular neurotransmitter and receptor phenotypes. Other phenotypes may develop over a more protracted time course compared to normal development. It is unlikely that the apoptotic degeneration of surrounding CPNs recreates an environment identical to that found in layers II/III and IV during development, with the correct complement of factors required to optimally direct neuronal maturation.

Linked to the first possibility that a variable delay in neurotransmitter and neurotransmitter receptor expression is attributable to environmental factors may be the intrinsic nature of the E17 neuroblasts themselves. For instance, there is evidence that although all neurotransmitters are present shortly after birth in the rodent cortex, GABA expression precedes the expression of the excitatory transmitters glutamate and aspartate (Cherubini et al., 1991; Kimura and Baughman, 1997). Therefore, developmental programs for the expression of each particular cortical phenotype may be both separate and activated in a time-dependent manner (for review, see Levitt et al., 1993). The neuroblasts dissociated for transplantation may be less equipped to respond to the environmental signals present, to initiate each intrinsic program required for the development of expression of a particular neurotransmitter or receptor at the rate they would during development. This may be the result of axotomy or the removal of cell-cell contacts during dissociation, or the neuroblasts' response to removal from a favorable environment. The transplanted neuroblasts may thus be delayed in their ability to activate one or more appropriate gene expression programs, and this delay may be more pronounced after transplantation to a novel environment than during normal development. Alternatively, minor apparent differences in the time courses of expression may result from both variable sensitivity of immunolabeling by each antibody and from the long intervals between the specific times chosen for analysis.

\section{Conclusions}

For successful cellular replacement therapy in highly complex circuitry in the CNS such as that in neocortex, it will be crucial for newly incorporated neuroblasts or precursors not only to rebuild the cellular circuitry anatomically, but also to reinstate function within these circuits by appropriate synaptic signaling. Newly incorporated neurons will need to migrate to correct locations, undergo precise differentiation, and integrate fully at the cellular and synaptic levels. Here we show for the first time that donor neuroblasts transplanted to regions of cortex undergoing targeted neuronal degeneration cannot only extend appropriate long-distance axonal projections to the contralateral cortex, and receive synapses from other neurons, but that they can differentiate with an extremely high degree of phenotypic fidelity. Donor neuroblasts under these conditions can express the appropriate complement of neurotransmitters and receptors to replace degenerated callosal projection neurons. Thus, transplanted neuroblasts can undergo highly specific and directed differentiation and integrate appropriately within complex host circuitry. The results of experiments presented here indicate that the transplantation of embryonic neuroblasts or precursors is a feasible method to replace degenerating neurons and re-form precise, appropriate, and functional cortical circuitry.

\section{REFERENCES}

Arai Y, Mizuguchi M, Takashima S (1997) Developmental changes of glutamate receptors in the rat cerebral cortex and hippocampus. Anat Embryol 195:65-70.

Ashley DM, Bol SJ, Waugh C, Kannourakis G (1993) A novel approach to the measurement of different in vitro leukemic cell growth parameters. Leukemia Res 17:873-882.

Baker BL, Morrow AL, Vergalla J, Paul SM, Jones EA (1990) Gammaaminobutyric acid (GABAA) receptor-function in a rat model of hepatic encephalopathy. Metab Brain Dis 5:183-193.

Barbarisi P, Fabri M, Conti F, Manzoni T (1987) D-[3H]Aspartate retrograde labelling of callosal and association neurons of somatosensory areas of I and II of cats. J Comp Neurol 263:159-178. 
Barbe MF, Levitt P (1995) Age-dependent specification of the corticocortical connections of cerebral grafts. J Neurosci 15:1819-1834.

Barde YA (1990) The nerve growth factor family. Prog Growth Factor Res 2:237-248.

Behar TN, Li YX, Tran HT, Ma W, Dunlap V, Scott C, Baker JL (1996) GABA stimulates chemotaxis and chemokinesis of embryonic cortical neurons via Ca dependent mechanisms. J Neurosci 16:1808-1818.

Benes F (1995) Altered glutamatergic and GABAergic mechanisms in the cingulate cortex of the schizophrenic brain. Arch Gen Psych 52:1015-1018.

Brose N, Huntley GW, Stern-Back Y, Sharma G, Morrison JH, Heinamann SF (1994) Differential assembly of coexpressed glutamate receptor subunits in neurons of rat and cerebral cortex. J Biol Chem 24:16780-16784.

Castro A, Tonder N, Sunde N, Zimmer J (1988) Fetal neocortical transplants grafted to cerebral cortex of newborn rats receive afferents from the basal forebrain, locus coereleus, and midline raphe. Exp Brain Res 69:613-622.

Castro A, Hogan T, Sørenson J, Klausen B, Danielsen E, Zimmer J Neafsey E (1991) Heterotopic neocortical transplants: an anatomical and electrophysiological analysis of host projections to occipital cortical grafts placed into sensorimotor lesions in newborn rats. Dev Brain Res 58:231-236.

Cherubini E, Gaiarsa JL, Yehezkel BA (1991) GABA: an excitatory neurotransmitter in early postnatal life. Trends Neurosci 14:515-519.

Clendening B, Hume RI (1990) Cell interactions regulate dendritic morphology and responses to neurotransmitters in embryonic chick sympathetic preganglionic neurons in vitro. J Neurosci 10:3992-4005

Cobas A, Alverez-Bolado G, Fairein A (1988) Transient GABA-like immunoreactive axons in the corpus callosum of perinatal rats. Neurosci Lett 93:7-12.

Cohen-Cory S, Dreyfus CF, Black IB (1991) NGF and excitatory neurotransmitters regulate survival and morphogenesis of cultured cerebellar Purkinje cells. J Neurosci 11:462-471.

Conti F, Manzoni T (1994) The neurotransmitters and postsynaptic actions of callosally projecting neurons. Behav Brain Res 64:37-53.

Conti F, Fabri M, Manzoni T (1988a) Glutamate positive neurons in the somatic sensory areas I and II of cats. J Neurosci 8:2948-2960.

Conti F, Fabri M, Manzoni T (1988b) Immunocytochemical evidence for glutamatergic cortico-cortical connections in monkeys. Brain Res 462:148-153.

Currie SN, Wang XF, Daw NW (1994) NMDA receptors in layers II and III of rat cerebral cortex. Brain Res 662:103-108.

Davis GW, Murphy RK (1994) Retrograde signaling and the development of transmitter release properties in the invertebrate nervous system. J Neurobiol 25:740-756.

Dinopoulis A, Dori I, Davies SW, Parnavelas JG (1989) Neurochemical heterogeneity among corticof ugal and callosal projection neurons. Exp Neurol 105:36-44.

Dori I, Dinopoulos A, Cavanagh ME, Parnavelas JG (1992) Proportion of glutamate- and aspartate-immunoreactive neurons in the efferent pathways of the rat visual cortex varies according to the target. J Comp Neurol 319:191-204.

Erdo SL, Wolff JR (1990) Postnatal development of the excitatory amino acid system in visual cortex of the rat. Changes in ligand binding to NMDA, quisqualate and kainate receptors. Int $\mathrm{J}$ Dev Neurosci 8:199-204.

Ernsberger U, Rohrer H (1988) Neuronal precursor cells in chick dorsal root ganglia: differentiation and survival in vitro. Dev Biol 126:420-432.

Eshkind LG, Leube RE (1995) Mice lacking synaptophysin reproduce and form typical synaptic vesicles. Cell Tissue Res 282:423-433.

Fagg GE, Mena EE, Cotman CW (1983) L-glutamate receptor populations in synaptic membranes: effects of ions and pharmacological characteristics. Adv Biochem Psychopharmacol 37:199-209.

Faingold CL, Millan MH, Boersma CA, Meldrum BS (1988) Excitant amino acids and audiogenic seizures in the genetically epilepsy-prone rat. I. Afferent seizure initiation pathway. Exp Neurol 99:678-686.

Favaron M, Manev RM, Rimland JM, Candeo P, Beccaro M, Manev H (1993) NMDA-stimulated expression of BDNF mRNA in cultured cerebellar granule neurones. NeuroReport 4:1171-1174.

Fink K, Zentner J, Gothert M (1994) Increased GABA release in the human brain cortex as a potential pathogenetic basis of hyperosmolar diabetic coma. J Neurochem 62:1476-1481.

Fox K, Schlaggar BL, Glazewski S, O'Leary DD (1996) Glutamate receptor blockade at cortical synapses disrupts development of thalamocortical and columnar organization in somatosensory cortex. Proc Natl Acad Sci USA 93:5584-5589.

Fykse EM, Takei K, Walch-Solimena C, Geppert M, Jahn R, De Camilli P, Sudhof TC (1993) Relative properties and localizations of synaptic vesicle protein isoforms: the case of the synaptophysins. J Neurosci 13:4997-5007.

Giuffrida R, Rustioni A (1989) Glutamate and aspartate immunoreactivity in cortico-cortical neurons of the sensorimotor cortex of rats. Exp Brain Res 74:41-46.

Gonchar YA, Johnson PB, Weinberg RJ (1995) GABA- immunopositive neurons in rat neocortex with contralateral projections to S-I. Brain Res 697:27-34

Gonzalez MF, Sharp FR (1987) Fetal frontal cortex transplanted to in- jured motor/sensory cortex of adult rats: reciprocal connections with host thalamus demonstrated with WGA-HRP. Exp Neurol 99:154-165.

Gordon B, Pardo D, Conant K (1996) Laminar distribution of MK-801, kainate, AMPA, and muscimol binding sites and the effect of dark rearing in rat visual cortex. J Comp Neurol 365:466-478.

Gordon B, Kinch G, Kato N, Keele C, Lissman T, Fu LN (1997) Development of MK-801, kainate, AMPA, and muscimol binding sites and the effect of dark rearing in rat visual cortex. J Comp Neurol 383:73-81.

Gotz M, Williams BP, Boltz J, Price J (1995) The specification of neuronal fate: a common precursor for neurotransmitter subtypes in the rat cerebral cortex in vitro. Eur J Neurosci 7:889-898.

Grabowski M, Brundin P, Johansson BB (1992) Fetal neocortical grafts implanted in adult hypertensive rats with cortical infarcts following a middle cerebral artery occlusion: ingrowth of afferent fibers from the host brain. Exp Neurol 116:105-121.

He Y, Janssen WGM, Vissavajjhala P, Morrison JH (1998) Synaptic distribution of GluR2 in hippocampal GABAergic interneurons and pyramidal cells: a double label immunogold analysis. Exp Neurol 150:1-13.

Hernit-Grant CS, Macklis JD (1996) Embryonic neurons transplanted to regions of targeted photolytic cell death in adult mouse somatosensory cortex re-form specific callosal projections. Exp Neurol 139:131-142.

Honig MG, Hume RI (1989) Carbocyanine dyes. Novel markers for labelling neurons. Trends Neurosci 12:333-335.

Huntley GW, Rogers SW, Moran T, Janssen W, Arcin N, Vickers JC, Cauley K, Heinemann SF, Morrison JH (1993) Selective distribution of kainate receptor subunit reactivity in monkey neocortex revealed by a monoclonal antibody that recognizes glutamate receptor subunits gluR 5/6/7. J Neurosci 13:2965-2981.

Huntley GM, Vickers JC, Janssen W, Brose N, Heinemann SF, Morrison JH (1994) Distribution and synaptic localization of immunocytochemically identified NMDA receptor subunit proteins in sensory-motor and visual cortices of monkey and human. J Neurosci 14:3603-3619.

Iacovitti L, Evinger MJ, Joh TH, Reis DJ (1989) A muscle-derived factor(s) induces expression of a catecholamine phenotype in neurons of cultured rat cerebral cortex. J Neurosci 9:3529-3537.

Isacson O, Sofroniew MV (1992) Neuronal loss or replacement in the injured adult cerebral neocortex induces extensive remodeling of intrinsic and afferent neural system. Exp Neurol 117:151-175.

Jansen EM, Solberg L, Underhill S, Wilson S, Cozzari C, Hartman BK, Faris PL, Low WC (1997) Transplantation of fetal neocortex ameliorates sensorimotor and locomotor deficits following neonatal ischemichypoxic brain injury in rats. Exp Neurol 147:487-497.

Jones EG (1986) Neurotransmitters in the cerebral cortex. J Neurosurg 65:135-153.

Kennedy TE, Tessier-Lavigne M (1995) Guidance and introduction of branch formation in developing axons by target-derived diff usible factors. Curr Opin Neurobiol 5:83-90.

Kimura F, Baughman RW (1997) GABAergic transcallosal neurons in the developing rat neocortex. Eur J Neurosci 9:1137-1143.

Kiser PJ, Cooper NG, Mower GD (1998) Expression of two forms of glutamic acid decarboxylase (GAD67 and GAD65) during postnatal development rat somatosensory barrel cortex. J Comp Neurol 402:62-74.

Koester SE, O'Leary DD (1993) Connectional distinction between callosal and subcortically projecting cortical neurons is determined prior to axon extension. Dev Biol 160:1-14.

Koller H, Siebler M, Schmalenbach C, Muller HW (1990) GABA and glutamate receptor development of cultured neurons from rat hippocampus, septal region, and neocortex. Synapse 5:59-64.

Landis SC (1990) Target regulation of neurotransmitter phenotype. Trends Neurosci 13:344-350.

Langui D, Sarhan S, Devilliers G, Pettmann B, Delaunoy JP, Seiler N (1988) Synapse formation and development of neurotransmitter functions in neuronal cells from chick brain cultured in a serum-free, defined medium. Int J Dev Neurosci 6:137-147.

Leavitt BR, Hernit-Grant CS, Macklis JD (1999) Mature astrocytes transform into transitional radial glia within adult mouse neocortex that supports directed migration of transplanted immature neurons. Exp Neurol 157:43-57.

Levitt P, Ferri RT, Barbe MF (1993) Progressive acquisition of cortical phenotypes as a mechanism for specifying the developing cerebral cortex. Perspect Dev Neurobiol 1:65-74.

Levitt P, Harvey JA, Friedman E, Simansky K, Murphy EH (1997) New evidence for neurotransmitter influences on brain development. Trends Neurosci 20:269-274.

Li YX, Zhang Y, Lester HA, Schuman EM, Davidson N (1998) Enhancement of neurotransmitter release induced by brain-derived neurotrophic factor in cultured hippocampal neurons. J Neurosci 18:10231-10240.

Lidow MS, Goldman-Rakic PS, Rakic P (1991) Synchronized overproduction of neurotransmitter receptors in diverse regions of the primate cerebral cortex. Proc Natl Acad Sci USA 88:10218-10221.

Lipton SA, Kater SB (1989) Neurotransmitter regulation of neuronal outgrowth, plasticity, and survival. Trends Neurosci 12:265-270.

Loscher W (1998) Pharmacology of glutamate receptor antagonists in the kindling of epilepsy. Prog Neurobiol 54:721-741.

Lummis SC, Gundlach AL, Johnston GA, Harper PA, Dodd PR (1990) Increased gamma-aminobutyric acid receptor function in the cerebral 
0cortex of myoclonic calves with an hereditary deficit in glycine/strychnine receptors. J Neurochem 55:421-426.

Macklis JD (1993) Transplanted neocortical neurons migrate selectively into regions of neuronal degeneration produced by chromophore targeted laser photolysis. J Neurosci 13:3848-3863.

Madison R, Macklis JD (1993) Noninvasively induced degeneration of neocortical pyramidal neurons in vivo: selective targeting by laser activation of retrogradely transported photolytic chromophore. Exp Neurol 121:153-159.

Madison R, Macklis JD, Thies C (1990) Latex nanosphere delivery system (LNDS): novel nanometer-sized carriers of fluorescent dyes and active agents selectively target neuronal subpopulations via uptake and retrograde transport. Brain Res 522:90-98.

Magavi SS, Leavitt BR, Macklis JD (2000) Induction of neurogenesis in the neocortex of adult mice. Nature 405:951-955.

Malizia AL, Cunningham VJ, Bell CJ, Liddle PE, Jones T, Nutt DJ (1998) Decreased brain GABA(A)- benzodiazepine receptor binding in panic disorder: preliminary results from a quantitative PET study. Arch Gen Psychiatry 55:715-720.

McCauley LD, Gee KW (1995) Influence of the estrus cycle on the discrimination of apparent neuroactive steroid site subtypes on the gammaaminobutyric acid. A receptor complex in the rat. J Pharmacol Exp Ther 275:1412-1417.

McCormick DA, Wang Z, Hugenard J (1993) Neurotransmitter control of neocortical neuronal activity and excitability. Cereb Cortex 3:387-398.

Meier E, Hertz L, Schousboe A (1991) Neurotransmitters as developmental signals. Neurochem Int 19:1-15.

Micheva KD, Beaulieu C (1995) Postnatal development of GABA neurons in the rat somatosensory barrel cortex: a quantitative study. Eur J Neurosci 7:419-430.

Mufson EJ, Labbe R, Stein DG (1987) Morphologic features of embryonic neocortex grafts in adult rats following frontal cortical ablation. Brain Res 401:162-167.

Oh KS, Lee CJ, Gibbs JW, Coulter DA (1995) Postnatal development of GABAA receptor function in somatosensory thalamus and cortex: whole-cell voltage-clamp recording in acutely isolated rat neurons. J Neurosci 15:1341-1351.

Olney JW, Farber NB (1995) Glutamate receptor dysfunction and schizophrenia. Arch Gen Psychiatry 52:998-1007.

Ozawa S, Kamiya H, Tsuzuki K (1998) Glutamate receptors in the mammalian central nervous system. Prog Neurobiol 54:581-618.

Paschen W, Schmitt J, Gissel C, Dux E (1997) Developmental changes of RNA editing of glutamate receptor subunits GluR5 and GluR6 in vivo versus in vitro. Brain Res Dev Brain Res 98:271-280.

Patterson PH (1978) Environmental determination of autonomic neurotransmitter functions. Annu Rev Neurosci 1:1-17.

Pellegri G, Magistretti PJ, Martin JL (1998) VIP and PACAP potentiate the action of glutamate on BDNF expression in mouse cortical neurones. Eur J Neurosci 10:272-280.

Poulter MO, Brown LA (1999) Transient expression of GABAA receptor subunit mRNAs in the cellular processes of cultured cortical neurons and glia. Brain Res Mol Brain Res 69:44-52.

Pozzo-Miller LD, Gottschalk W, Zhang L, McDermott K, Du J, Gopalakrisshnan R, Oho C, Zheng ZH, Lu B (1999) Impairments in high-frequency transmission, synaptic vesicle docking, and synaptic protein distribution in the hippocampus of BDNF knockout mice. J Neurosci 19:4972-4983.

Qu M, Mittmann T, Luhmann HJ, Schleicher A, Zilles K (1998) Longterm changes of ionotropic glutamate and GABA receptors after unilateral permanent focal cerebral ischemia in the mouse brain. Neuroscience 85:29-43.

Retz W, Kornhuber J, Riederer P (1996) Neurotransmission and the ontogeny of human brain. J Neural Transm (Budapest) 103:403-419.

Rogers SW, Twyman RE, Gathring LC (1996) The role of autoimmunity to glutamate receptors in neurologic disease. Mol Med Today 2:76-81.

Saito S, Kobayashi S, Ohashi Y, Igarashi M, Kormiya Y, Ando S (1994) Decreased synaptic density in aged brains and its prevention by rearing under enriched environment as revealed by synaptophysin contents. J Neurosci Res 39:57-62.

Sala R, Viegi A, Rossi FM, Pizzorusso T, Bonanno G, Raiteri M, Maffei L (1998) Nerve growth factor and brain-derived neurotrophic factor increase neurotransmitter release in the rat visual cortex. Eur J Neurosci 10:2185-2191.

Scharff C, Kirn J, Grossman M, Macklis JD, Nottebohm F (2000) Targeted neuronal death affects neuronal replacement and vocal behavior in adult songbirds. Neuron 25:481-492.

Schulz MK, Hogan TP, Castro AJ (1993) Connectivity of fetal neocortical block transplants in the excitotoxically ablated cortex of adult rats Exp Brain Res 96:480-486.

Schulz MK, McNulty JA, Handa RJ, Hogan TP, Tillotson GL, Shaw PL, Zimmer J, Castro AJ (1995) Fetal neocortical transplants grafted into neocortical lesion cavities made in newborn rats: an analysis of transplant integration with the host brain. Cell Transpl 4:123-132.

Shaw PJ, Ince PG (1997) Glutamate, excitotoxicity, and amyotrophic lateral sclerosis. J Neurol 244:S3-S14.

Shaw C, Lanius RA (1992) Cortical AMPA receptors: age dependent regulation by cellular depolarization and agonist stimulation. Brain Res Dev Brain Res 68:225-231.

Sheen VL, Macklis JD (1994) Apoptotic mechanisms in targeted neuronal cell death by chromophore activated photolysis. Exp Neurol 130:67-81.

Sheen VL, Macklis JD (1995) Targeted neocortical neuronal cell death in adult mice guides migration and differentiation of transplanted embryonic neurons. J Neurosci 15:8378-8392.

Sheen VL, Arnold MW, Wang Y, Macklis JD (1999) Neural precursor differentiation following transplantation into neocortex is dependent on intrinsic developmental state and receptor competence. Exp Neurol 158:47-62.

Sieber-Blum M (1991) Role of the neurotrophic factors BDNF and NGF in the commitment of pluripotent neural crest cells. Neuron 6:949-955.

Snyder EY, Yoon C, Flax JD, Macklis JD (1997) Multipotent neural precursors can differentiate toward replacement of neurons undergoing targeted apoptotic degeneration in adult mouse neocortex. Proc Natl Acad Sci USA 94:11663-11668.

Sørensen JC, Wanner-Olsen H, Tøder N, Danielsen E, Castro AJ, Zimmer J (1990) Axotomized, adult basal forebrain neurons can innervate fetal frontal cortex grafts: a double fluorescent tracer study in the rat. Exp Brain Res 92:299-309.

Sørensen JC, Grabowski M, Zimmer J, Johansson BB (1996) Fetal neocortical tissue blocks implanted in brain infarcts of adult rats interconnect with the host brain. Exp Neurol 138:227-235.

Stein DG, Mufson EJ (1987) Morphological and behavioral characteristics of embryonic brain tissue transplants in adult, brain-damaged subjects. Ann NY Acad of Sci 495:444-463.

Takei N, Sasaoka K, Inoue K, Takahashi M, Endo Y, Hatanaka H (1997) Brain-derived neurotrophic factor increases the stimulation-evoked release of glutamate and the levels of exocytosis-associated proteins in cultured cortical neurons from embryonic rats. J Neurochem 68:370-375.

Thiel G (1993) Synapsin I, synapsin II, and synaptophysin: marker proteins of synaptic vesicles. Brain Pathol 3:87-95.

Thoenen H (1995) Neurotrophins and neuronal plasticity. Science 270:593-598.

Tsumoto T (1990) Excitatory amino acid transmitters and their receptors in neural circuits of the cerebral neocortex. Neurosci Res 9:79-102.

Valouskova V, Galik J (1995) Unilateral grafting of fetal neocortex into a cortical cavity improves healing of a symmetric lesion in the contralateral cortex of adult rats. Neurosci Lett 186:103-106.

Van Eden CG, Palmer R, Lichtensteiger W, Schlumpf M (1995) Laminar distribution of GABAA receptor alpha1, beta1, and gamma2 subunit mRNAs in the granular and agranular frontal cortex of the rat during pre- and postnatal development. Cereb Cortex 5:234-246.

Vickers JC, Huntley GW, Edwards AM, Moran T, Rogers SW, Heimemann SF, Morrison JH (1993) Quantitative localization of AMPA/kainate and kainate glutamate receptor subunit immunoreactivity in neurochemically identified subpopulations of neurons in the prefrontal cortex of the macaque monkey. J Neurosci 13:2982-2992.

Voigt T, LeVay S, Stamnes MA (1988) Morphological and immunocytochemical observations on the visual callosal projections in the cat J Comp Neurol 272:450-460.

Wang Y, Sheen VL, Macklis JD (1998) Cortical interneurons upregulate neurotrophins in vivo in response to targeted apoptotic degeneration of neighboring pyramidal neurons. Exp Neurol 154:389-402.

Weiss SA, Albers DS, Iadarola MJ, Dawson TM, Dawson VL, Staendart DG (1998) NMDAR1 glutamate receptor subunit isoforms in neostriatal neocortical, and hippocampal nitric oxide synthase neurons. J Neurosci 18:1725-1734.

Widmer HR, Hefti F (1994) Stimulation of GABAergic neuron differentiation by NT- $4 / 5$ in cultures of rat cerebral cortex. Brain Res Dev Brain Res 80:279-284.

Yirmiya R, Zhou FC, Holder MD, Deems DA, Garcia J (1988) Partial recovery of gustatory function after neural tissue transplantation to the lesioned gustatory neocortex. Brain Res Bull 20:619-625.

Zhang L, Rubinow DR, Ma W, Marks JM, Feldman AN, Barker JL, Tathan TA (1998) GABA receptor subunit mRNA expression in brain of conflict, yoked control and control rats. Brain Res Mol Brain Res 58:16-26.

Zhang L, Chang YH, Feldman AN, Ma W, Lahjouji F, Barker JL, Hu Q, Maric D, Li BS, Li W, Rubinow DR (1999) The expression of GABA(A) receptor alpha2 subunit is upregulated by testosterone in rat cerebral cortex. Neurosci Lett 265:25-28.

Zhou J, Bradford HF (1997) Nerve growth factors and the control of neurotransmitter phenotype selection in the mammalian central nervous system. Prog Neurobiol 53:27-43. 